\title{
نشأة مصطلح الاقتصاد السياسي في العالم الإسلامي دراسة مقارنة بين الأدبيات العربية والتركية والأُردية
}

عبد الززاق بلعباس"

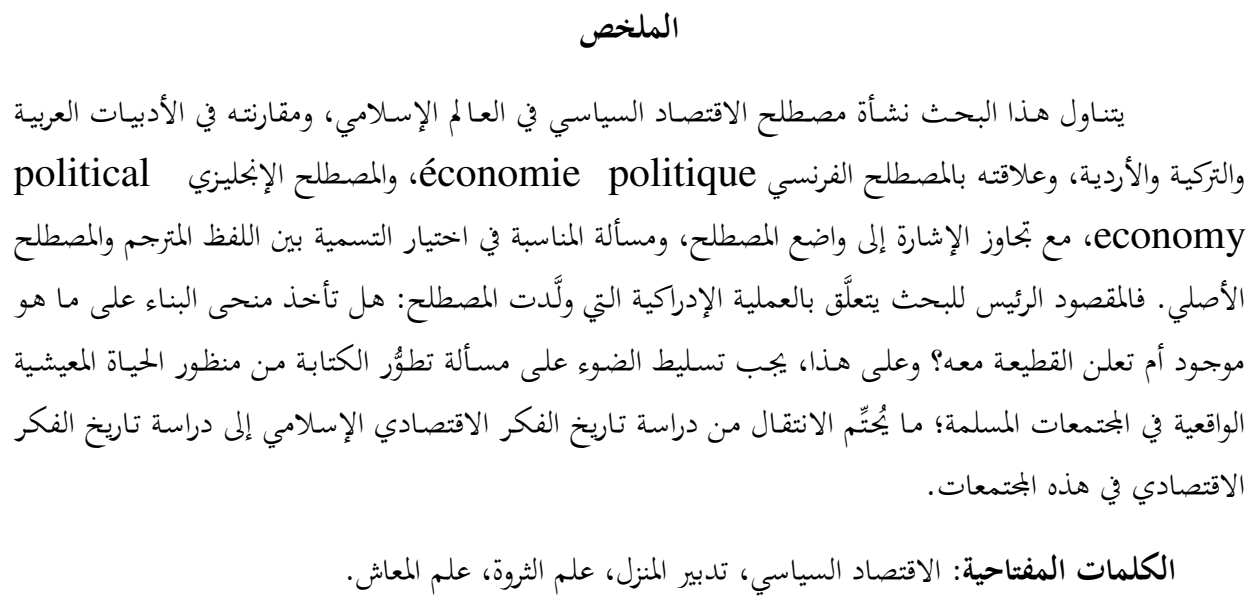

The Genesis of the Concept of Political Economy in the Muslim World

A Comparative Study between Arab, Turkish and Urdu Literature

\begin{abstract}
This study deals with the origin of the concept of 'political economy' in the Muslim world through a comparison between Arabic, Turkish and Urdu literature. The study found that the concept entered the Muslim world through the translation of the French term 'économie politique' and the English term 'political economy'. The study recommends going beyond the concern of who introduced first the concept, and the suitability of the translated or original terms. The central issue is the cognitive process that has generated the concept; whether adopting a constructive approach to what exists or to break with it. The study recommends shedding light on the evolution of writings on the economic life in Muslim societies and calls for a transition from the study of the history of economic thought in Islam to the history of economic thought in Muslim societies.
\end{abstract}

Key-words: Political economy, Management of the household, Science of wealth, Science of livelihood

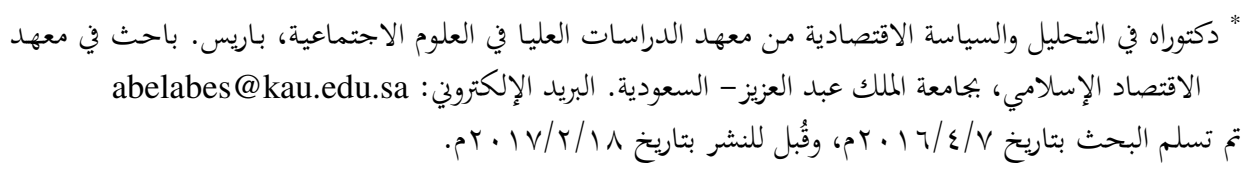




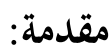

اهتمّ المسلمون على مدار العصور بحياتم المادية على اختلاف جوانبها ومستوياتما،

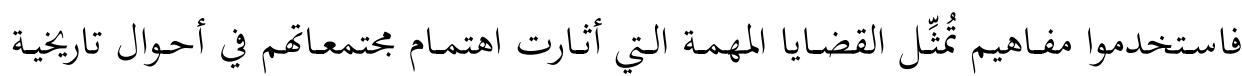

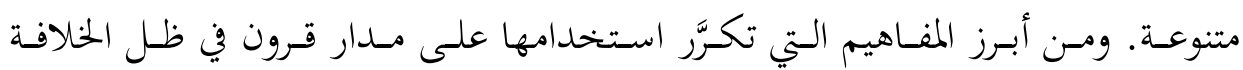

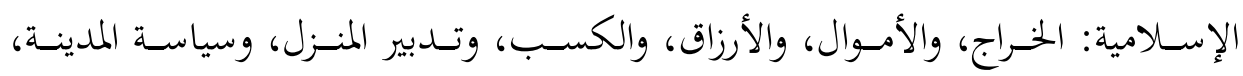

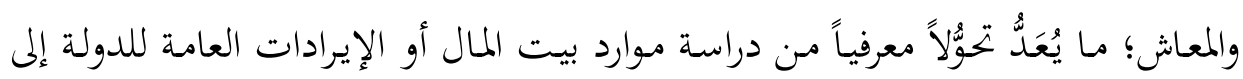

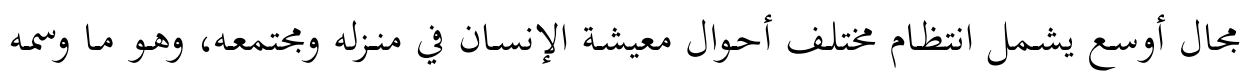
ابن خلدون بأوجهه معاش العمران البشري أو الاجتماع الإنساني، وسماه بعض التعان المتأخرين

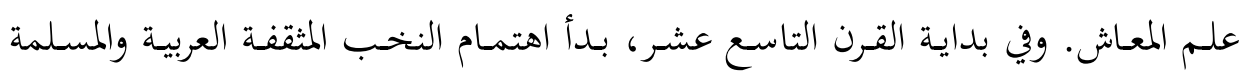
بالاقتصـاد السياسي بنـاءً على مـا وقفـت عليـهـ مـن كتابـات عـن هـــا الفـن بـاللغتين: الفرنسية، والإبحليزية.

تدور قضية البحث الجوهرية حول التساؤل الرئيس الآتي: ما الظروف والأحوال التي

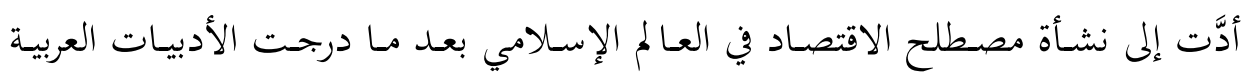

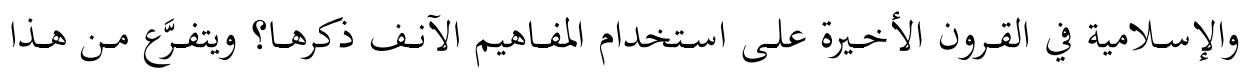
السؤال أسئلة ثانويـة، هي: مستى دخـل مصطلح الاقتصـاد السياسي في أدبيـات العـالم

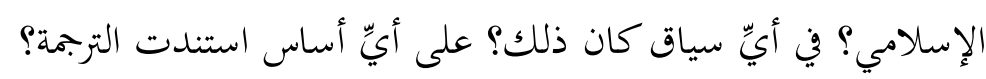
وننوه في ختام هذه المقدمة إلى أننا ترجمنا البيانات المتعلقة بالمصادر المتنوعة التي رجع

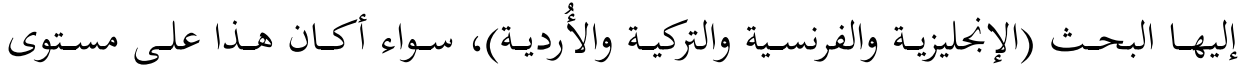

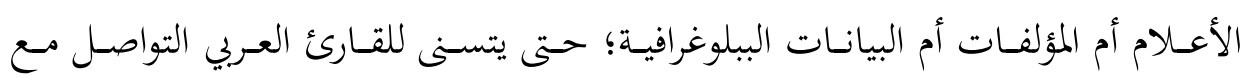
الأفكار الواردة في هذا البحث دون أي عائق لغوي. 


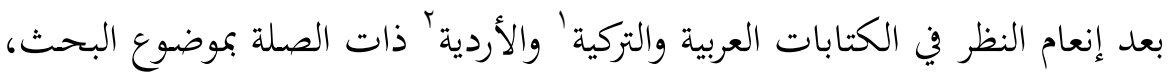
فقد ارتأينا تصنيفها في أربعة محاور رئيسة، هي: إنعام النظية واتركية

\section{ا ـ كتابة المصطلح الأصلي الفرنسي أو الإنجليزي بحروف اللغـة العربيـة، أو}

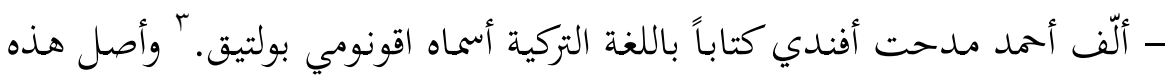
التسمية مشتق من المصطلح الفرنسي économie politique.

r. إعادة الاعتبار إلى المفاهيم التي اندثرت، مثل: تدبير المنزل، والمعاش:

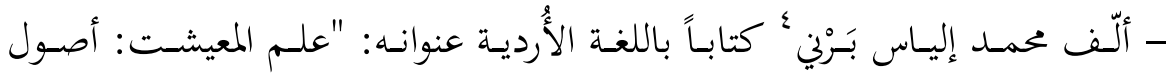

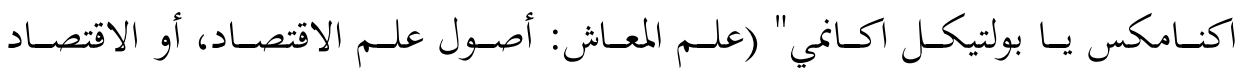

- إشارة محمد بنحاة الله صديقي في مقالة له بالإنحليزية عنواهـا: "منهجية الاقتصاد

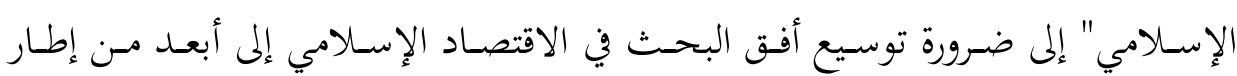

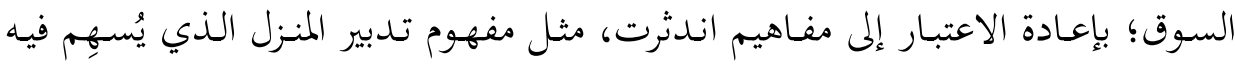

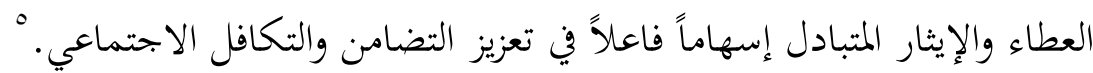

' المقصود بالتركية في هذا البحث هي اللغة العثمانية أو التركية القديمة، التي تشترك في حروف هجائها مع اللغة العربية

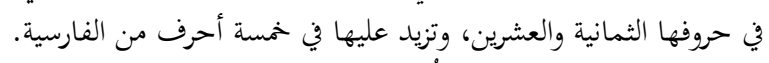

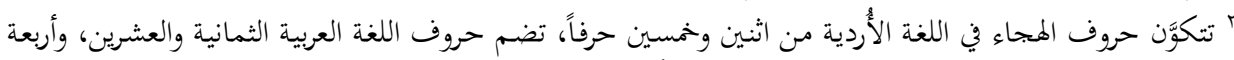

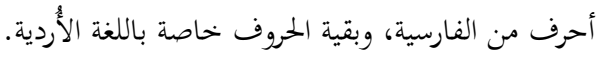

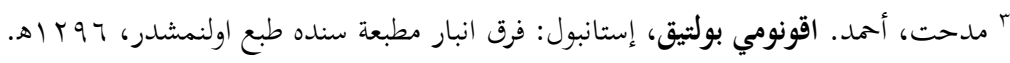

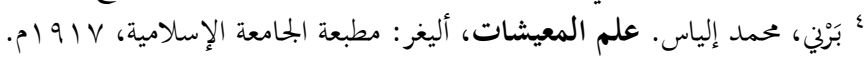
${ }^{5}$ Siddiqi, Muhammad Nejatullah. Methodology of Islamic Economics, In: Handbook on Islam and Economic Life, edited by M. Kabir Hassan and Mervyn K. Lewis, Chentelham: Edward Elgar, 2014, p. 86-87.

- صدّيقي، حممد بناة الله. منهجية الاقتصاد الإسلامي، ضمن: الإسلام والحياة الاقتصادية، تحرير : حممد كبير

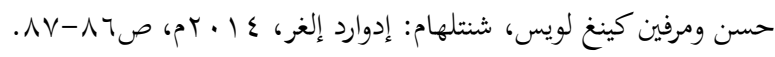


- إشـارة عبـد الرزاق بلعبـاس في ورقـة علميـة عنواهـا: "الاقتصـاد الإسـلامي: حفريـة مصطلح" إلى أنَّ إشكالية البحث في الاقتصاد الإسلامي بدأت أساساً من تبني مصطلح الاقتصاد الذي لم ينبثق عن المنظومة الحضارية العربية الإسلامية بناءً على التراكم المعرفي؛

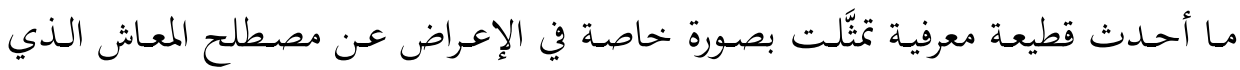
استقر عليه الفقهاء والأدباء في القرون الأخيرة.

ب. الربط بين مصطلح المعاش (أو الحياة المعيشية) ومصطلح الاقتصاد: - تعريـف عبــ القـادر البحـاوي، وعمـر بريهمـات في كتابهمـا "المرصـاد في مسـائل الاقتصاد" الاقتصاد السياسي بأنَّه "تدبير اجتماعي يقصد به إنماء ثروة الأمُة، وتقسيمها على الأفراد، وإنفاقها في سبيل الرفاهية، وتحسـين أحسوال المعاث، وترقيـة البلاد في سُسَّم V" الحضارة والمدنية.

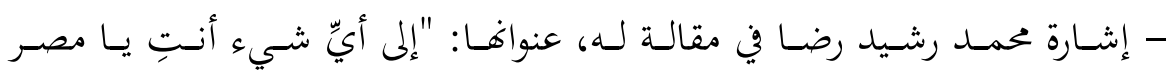
أحوج؟"، إلى أنَّ الحـال التي انفرد بهـا هـا العصر "هي أنَّ جميع الأمـم الراقية تنازع أهله

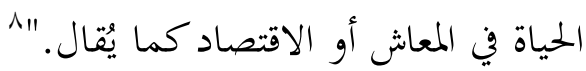

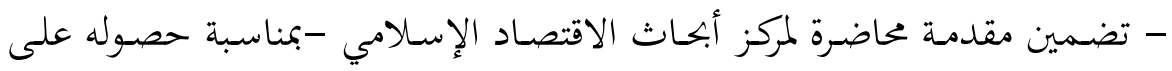

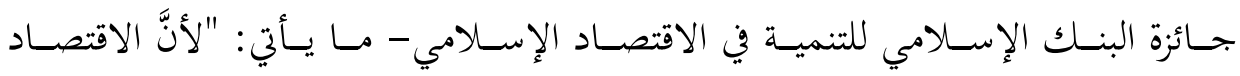

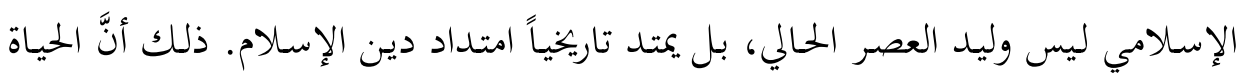
المعيشية التي يُعنى بهـا علم الاقتصـاد قـد تناولتها الشريعة الإسـلامية بالإصـلاح والتزكيـة

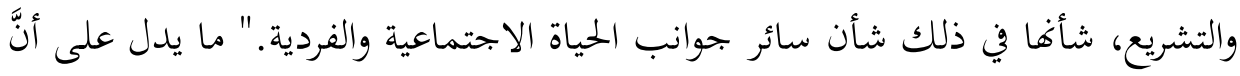
موضوع علم الاقتصاد هو الحياة المعيشية بحسب تصوُّر هذه المؤسسة البحثية العريقة.

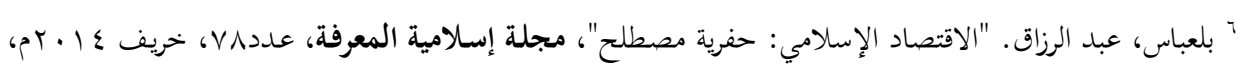
صه.

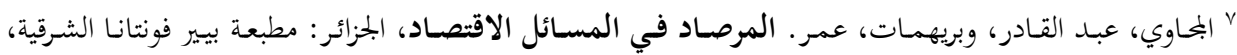

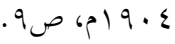

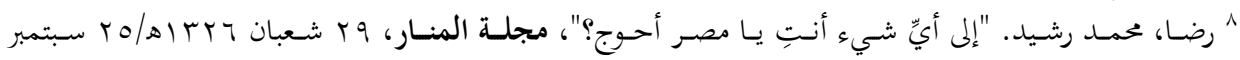

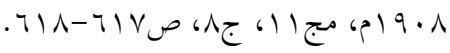

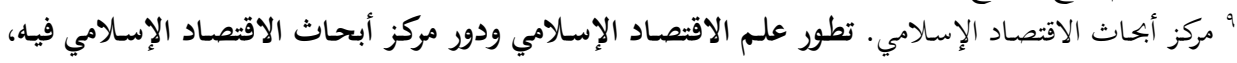

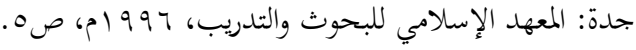


- إشارة محمد أنس الزرقا في ورقة قدَّمها للمؤتمر العالمي السابع للاقتصاد الإسلامي

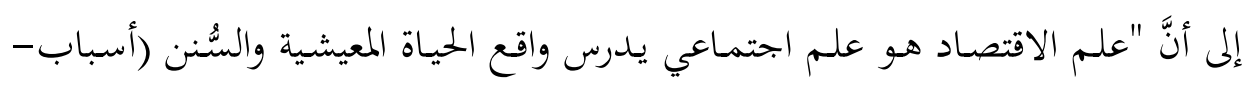

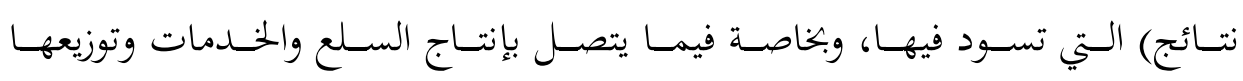

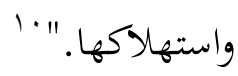

- تعريف عبدالجبار السبهاني الاقتصـاد بقوله: "الاقتصاد لغـة: مـن القصـد، وهـو

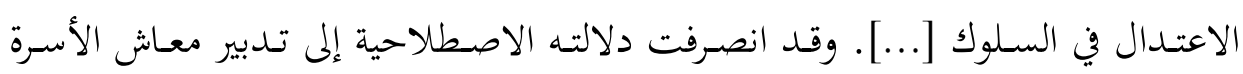

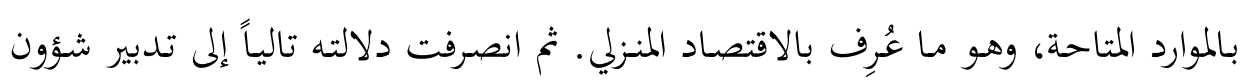

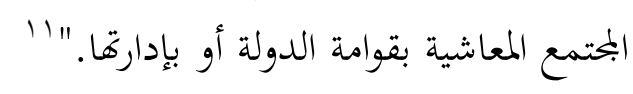

ع. تناول مسألة المناسبة والدّقة التي طرحها بعض الباحثين بخصوص ترجمة

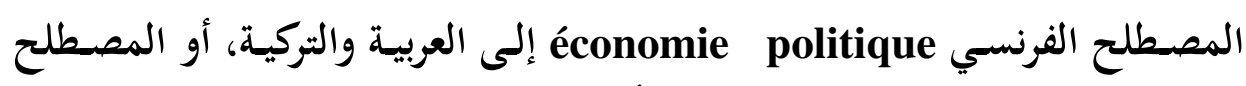
الإنجليزي political economy إلى الأُردية:

- إشارة جرجي زيدان في كتابه "تاريخ آداب اللغة العربية" إلى أنَّ تسمية المعاش هي

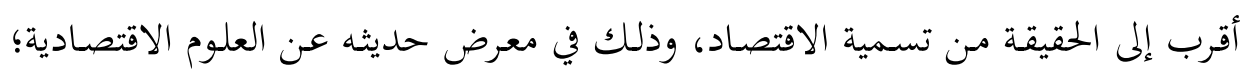

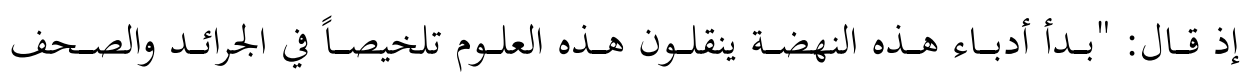

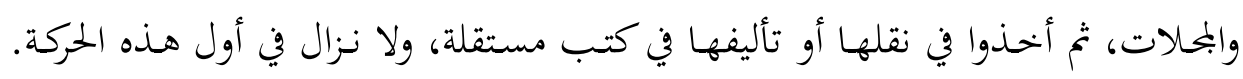

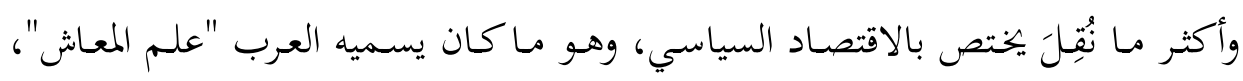

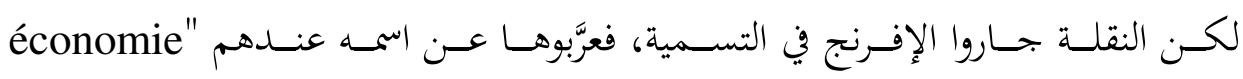
politique

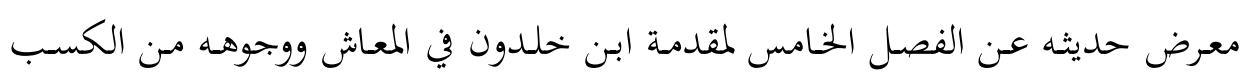

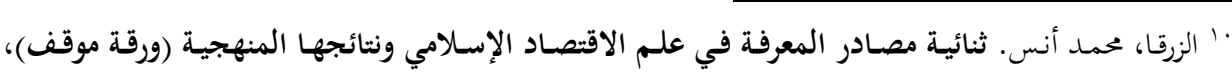

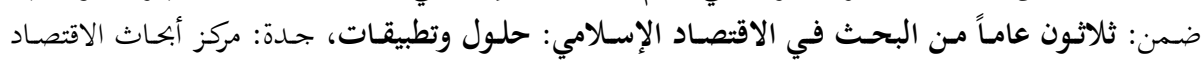

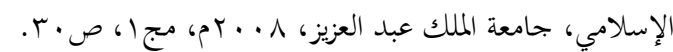

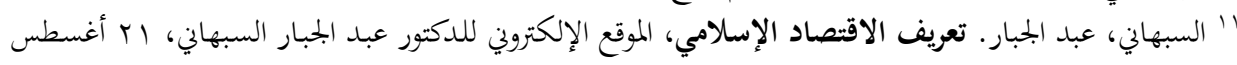


والصـنائع، قـال: "وهـو مـن الأبحاث المعاشية التي يسميها أهـل هـذا الزمـان "الاقتصـاد

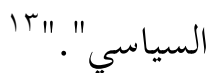

- تضـمين شـوقي ضـيف (رئيس بحمـع اللغـة العربيـة بالقـاهرة سـابقاً) كتابيـه: "في

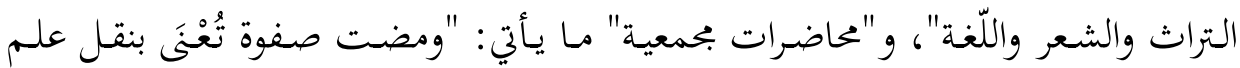

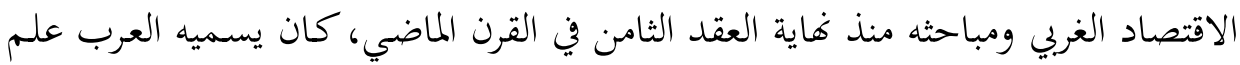

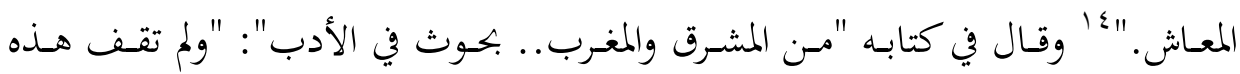

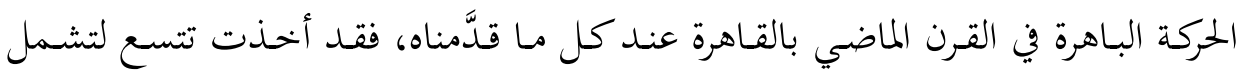

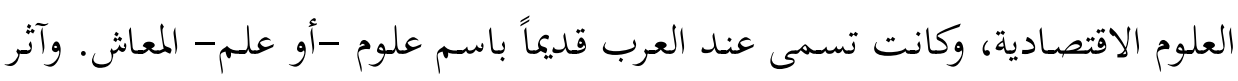

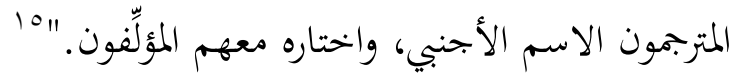

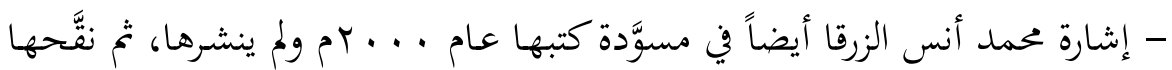

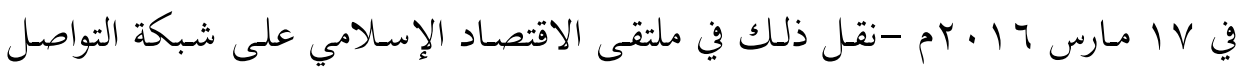

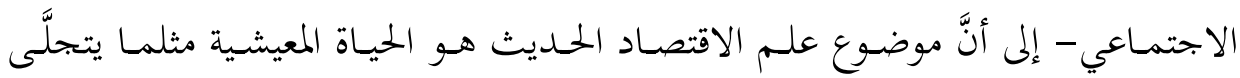

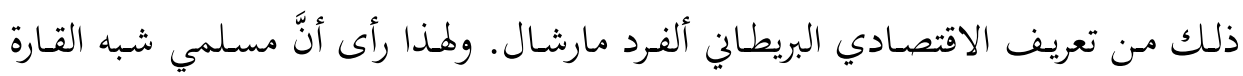

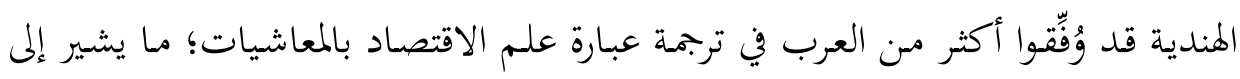

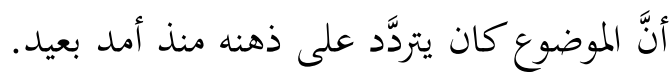

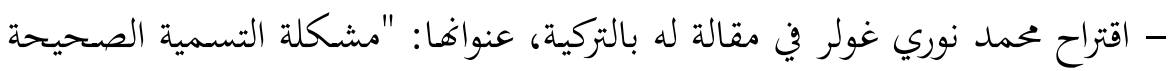

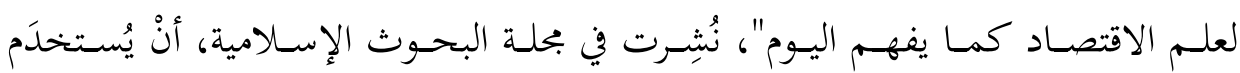

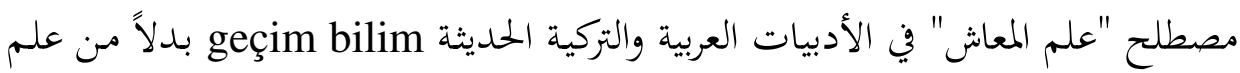
الاقتصاد economics.

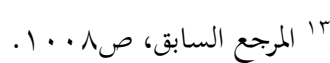

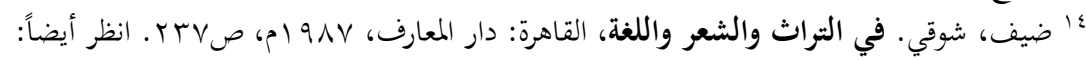

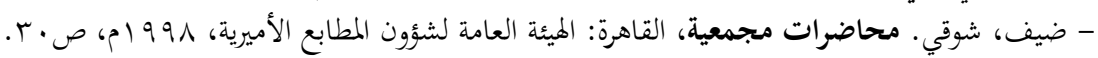

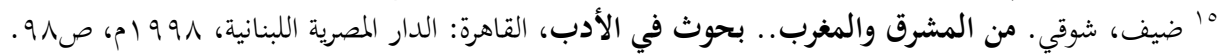
${ }^{16}$ Güler, Mehmet Nuri. Günümüzdeki iktisat (ekonomi) bilimi’nin adlandirilma problematiği, İslâmî Araştırmalar Dergisi, Cilt: 18, Sayi: 4, 2005, Sayfa: 377-386.

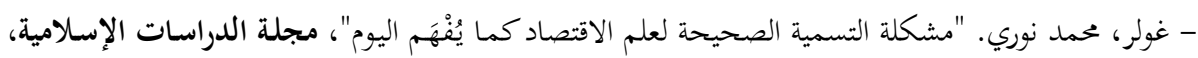

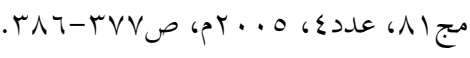




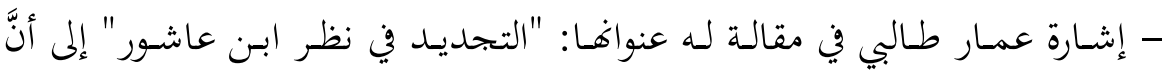

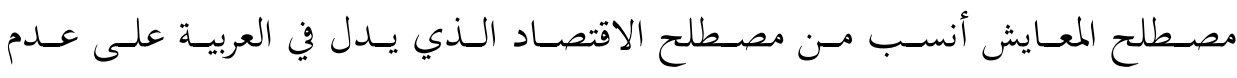

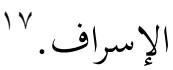

- طرح فضل عبد الكريم وعبد الرزاق بلعباس في ورقة عنواها: "الاقتصاد الإسلامي

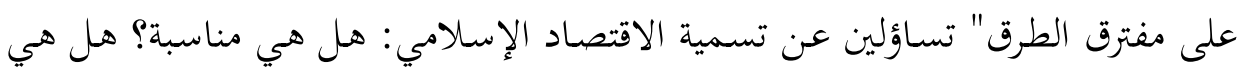

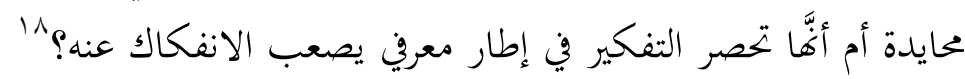

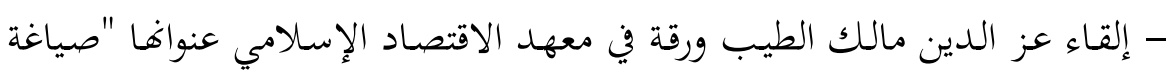
نظرية علم المعاش أو التأصيل الإسلامي للنظرية الاقتصادية"، أشار فيها إلى أنَّ مصطلح الاقتصاد يُمثّل عائقاً أمام صياغة نظرية إسلاصيل الإسلافية للحياة المعيشية. 19 وهذا المبحث لا يخص الأدبيات العربية والإسلامية وحددها، فقد أكَّد الاقتصادي

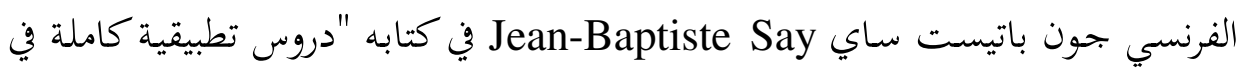

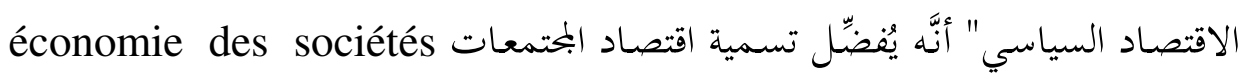

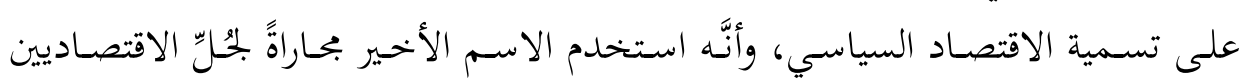
الذين اصطلحوا عليه.

وفي السياق نفسه، كتب باحث من مركز أبحاث الاقتصاد بجامعة كوريا إسمه هون

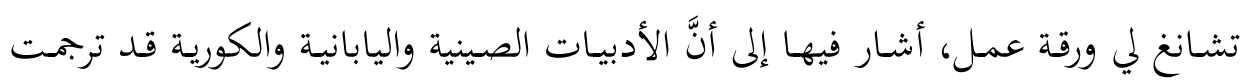

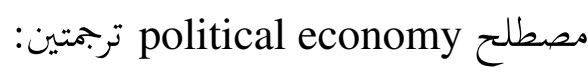

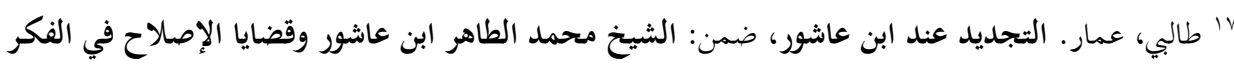

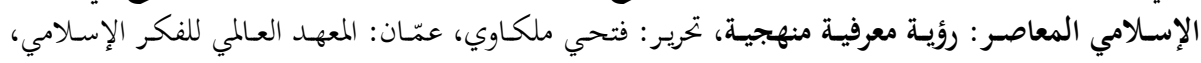

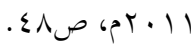

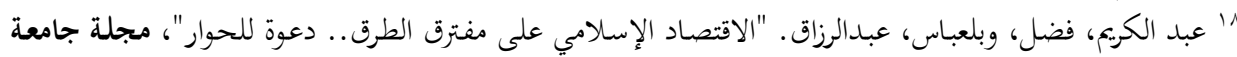

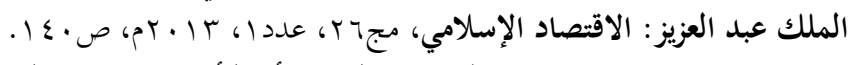

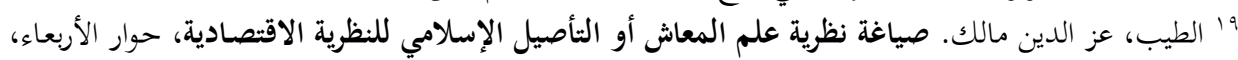

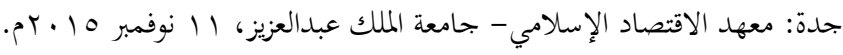

${ }^{20}$ Say, Jean-Baptiste. Cours complet d'économie politique pratique, Bruxelles: Société typographique belge, 1844, p. 2.

- سـاي، جـون باتيست. دروس تطبيقيـة كاملـة في الاقتصـاد السياسي، بروكسل: شركة النشر البلجيكية، 


$$
\begin{aligned}
& \text { الأولى: "經濟學" ترجمة بحسب المعنى، وتعني فن تدبير رفاهة الشعب. }
\end{aligned}
$$

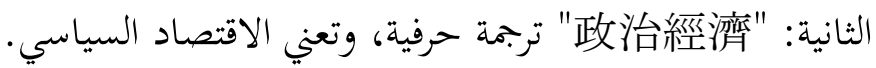

وقد استنتج الباحث أنَّ الترجمة الأولى تبدو أكثر ملاءمة اليوم؛ نظراً إلى تناغمها مع تطوُرات البحث العلمي الذي بات يولي البُعْد التاريخي، والمؤسسي، والسياسي، والثقافي

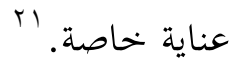

\section{ثانياً: تحديد وضع المصطلح معرفياً ومنهجية البحث}

بالرغم من هذه التساؤلات التي أُثيرت على مدار أكثر من قرن ضمن مُدَد منقطعة،

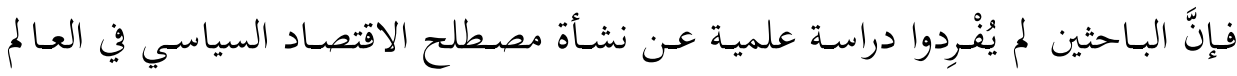
الإسـلامي، ولم يولـوا الأبحاث التي تناولت نشـأته في الأدبيـات غـير العربيـة والإسـلامية

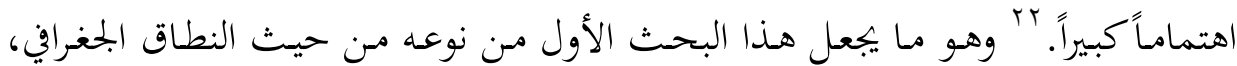

${ }^{21}$ Lee, Hun-Chang. Concepts and Translations of Political Economy and Economics, Discussion Paper Series No.0807, The Institute of Economic Research - Korea University, November 2008.

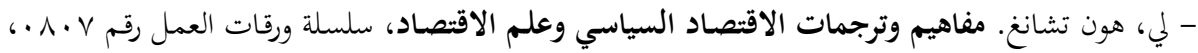

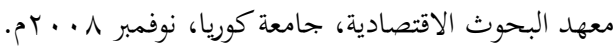

${ }^{22}$ Diemer, Arnaud and Guillemin, Hervé. La naissance de l'économie politique ou la fascination des penseurs de la société pour la physique, Triangle, ISH Lyon, Séminaire Economie Politique, 15 avril 2013; Bülbül, Yasar, Transfer of Political Economy by a Traditional Society: Ilm-i Tedbir-i Menzil in the Ottoman Empire, Actas de las XIII Jornadas de Epistemología de las Ciencias Económicas, ed. Alejandro Gabriel Miroli and Diego Mauricio Weisman, Universidad de Buenos Aires: CIECE Centro de Investigación en Epistemología de las Ciencias Económicas, December 2007, First edition, Buenos Aires; Winch, Donald. Riches and Poverty: An Intellectual History of Political Economy in Britain, 1750-1834, Cambridge: Cambridge University Press, 1996; Ordeshook, Peter C. The Emerging Discipline of Political Economy, In: Perspectives on Positive Political Economy, edited by James E. Alt, Kenneth A. Shepsle, Cambridge: Cambridge University Press, 1990, pp. 9-30; Gilles, Philippe and Berlan, Jean-Pierre. Économie, Histoire et genèse de l'économie 


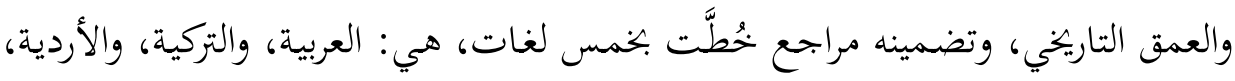

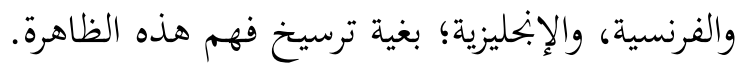

يمكن إجمال القضية التي يناقشها البحث في السؤال الآتي: ما أسباب نشأة مصطلح

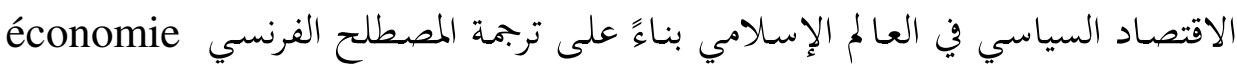

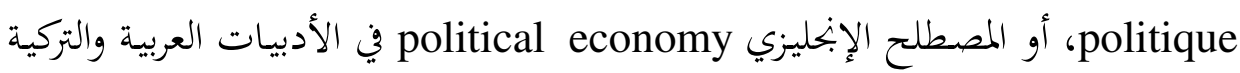
والأردية؟ يمكن الإجابة عن هذا السؤال بالفرضيات الآتية التي تتطلَّب الكثير من التحليل والتمحيص: ا ـ ترجمة المصطلح مردُها الانبهار بالحضارة الأوروبية، وولع المغلوب بالغالب. r. أكثر مَن رسَّخ المصطلح هـم المترجمون من اللغات الأوروبية إلى العربية والتركية

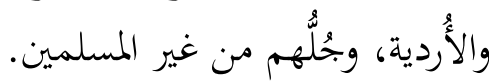

r. ترجمـة المصـطلح مردُهــا إهـال المسـلمين العلـوم الاجتماعيـة، وتقصـيرهم فيها، بالرغم من حاجتهم الشديدة إليها.

politique: Quesnay, Turgot et Condorcet, Say, Sismondi, Revue économique, 1991, Volume 42, Numéro 2, pp. 367-394.

- ديمر، أرنو وغيومان، هِرفي. "نشأة علم الاقتصاد السياسي أو انبهار مفكري مؤسسة علم الفيزياء الفرنسية"،

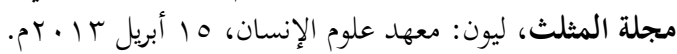

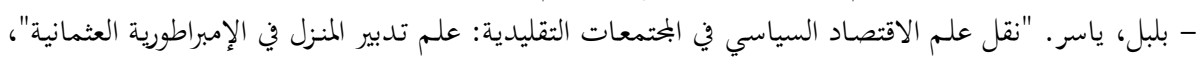

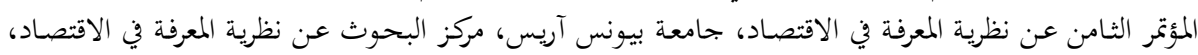

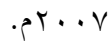

- وينش، دونالد. الأثرياء والفقر: تاريخ فكري للاقتصاد السياسي في بريطانيا من • • V ام إلى ع ع ام ام،

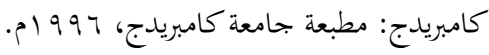

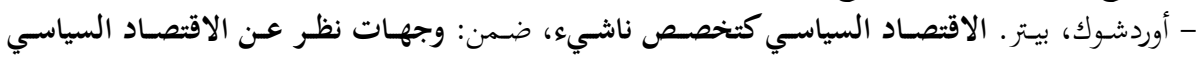

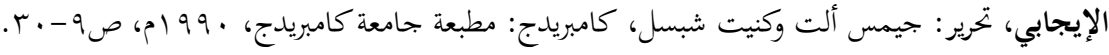

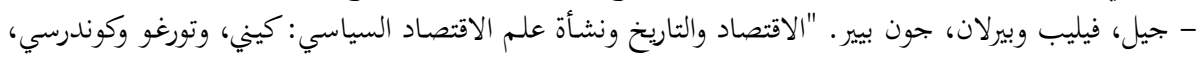

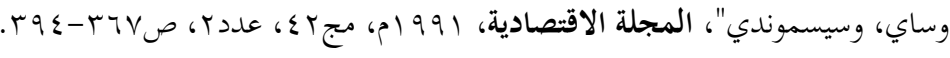


ولهذا، لا يجبـب الاكتفـاء بالإشـارة إلى واضع المصطلح التي استأترت باهتمـام بعض

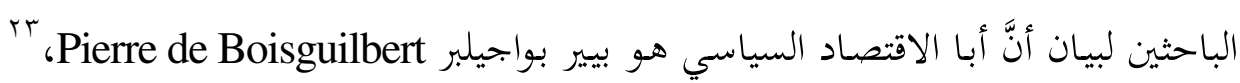

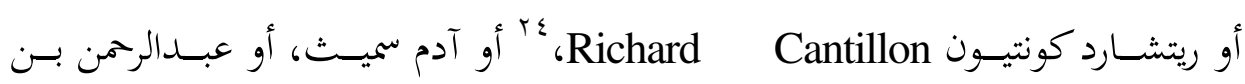

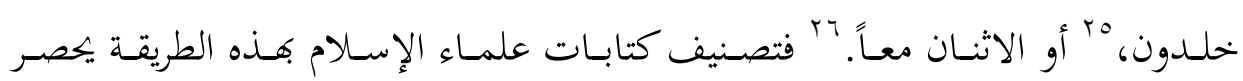
التفكير في ثنائية أوروبا والإسلام، ويجعل استخدام مصطلح الاقتصاد السياسي في زمن لم

${ }^{23}$ Hecht, Jacqueline. Pierre de Boisguilbert ou la naissance de l'économie politique, Population, 1967, Volume 22, Numéro 1, pp. 111-116; Cadet, Félix. Pierre de Boisguilbert: précurseur des économistes, Paris: Institut Copet, 2014.

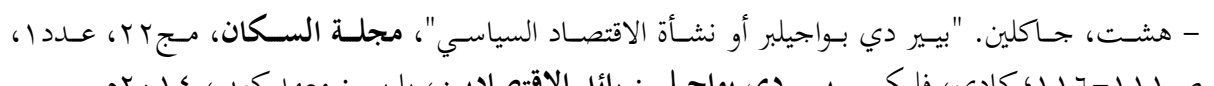

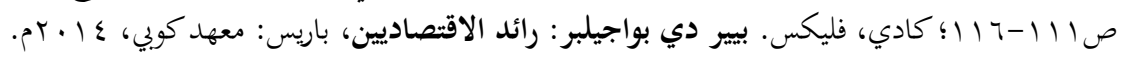

24 Thornton, Mark. Richard Cantillon and the Origin of Economic Theory, Journal des Économistes et des Études Humaines, Volume 8, Issue 1, March 1998, pp. 61-74.

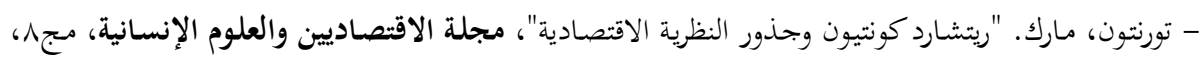

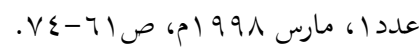

${ }^{25}$ Lacoste, Yves. Maghreb: peuples et civilizations, Paris: La Decouverte, 1995, p. 17 ; Oweiss, Ibrahim. Ibn Khaldun, the Father of Economics, Goerges Atiyeh. Arab Civilization: Challenges and Responses - Studies in Honor of Dr.Constantine Zurayk, New York: State University of New York, 1988, p. 112-127; McCaffrey, Joe. Ibn Khaldun: The Forgotten Father of Economics, ISOR Journal of Business and Management, 16(3), 2014, pp. 1-3.

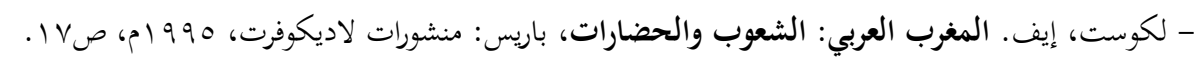

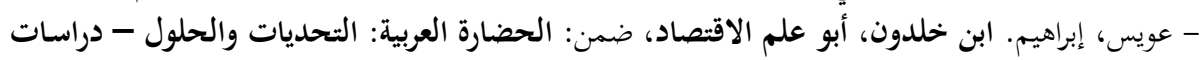

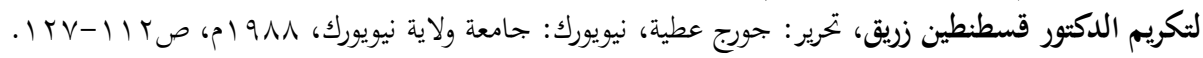

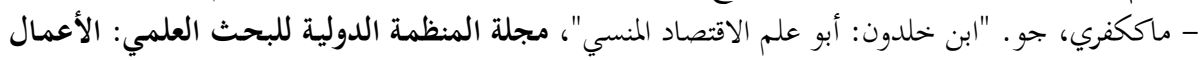

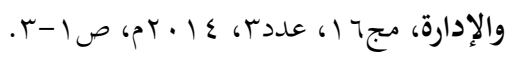

${ }^{26}$ Ea, Hamed A. and Eid, Nada H. Between Ibn Khaldun and Adam Smith (Fathers of Economics), IOSR Journal of Business and Management, Vol. 16, Issue 3, Ver. III, February 2014, pp. 54-56.

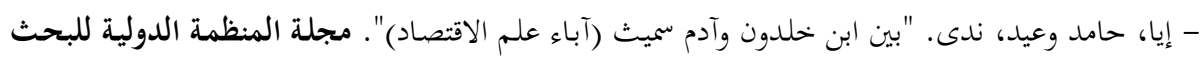

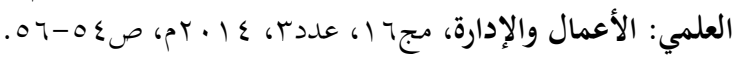


يظهر فيهه بعلُ.. ولهذا كله من الأخطاء المستفحلة التي نلمسها في أدبيات الاقتصاد

$$
\text { الإسلامي بدافع إبراز محاسن الإسلام. }
$$

وزيـادةً على ذلك، يتجـاوز البحثث مسـألة المناسبة في اختيـار التسـمية بين اللفظـ

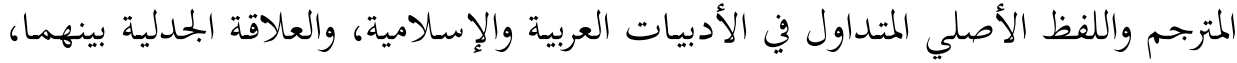

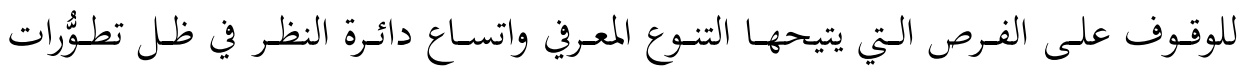

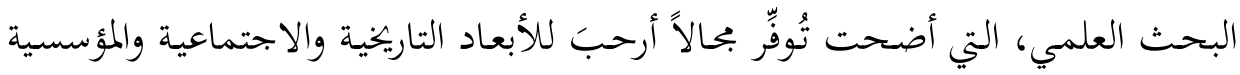

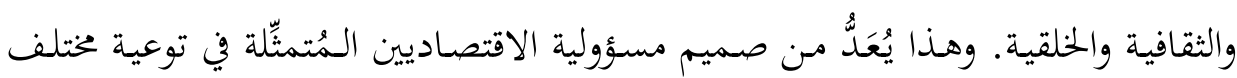

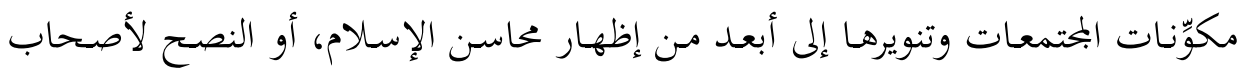

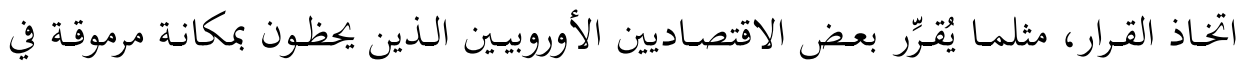

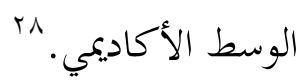

ومسن هنـا، تتجلَّى خطـة البحـث الـتي بتمـع بـين الأسـلوب التـاريخي والوصـفي

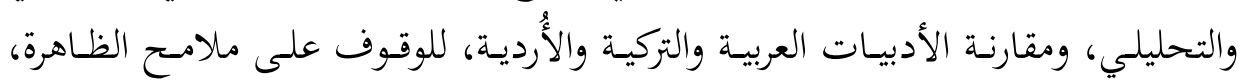

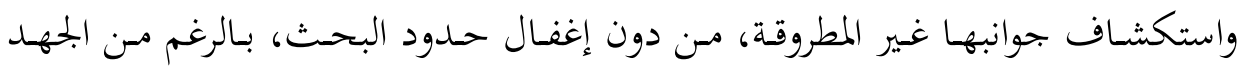

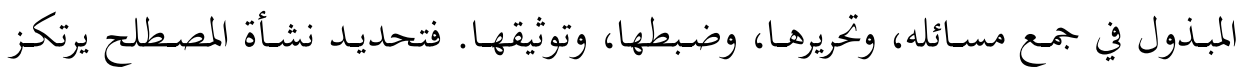

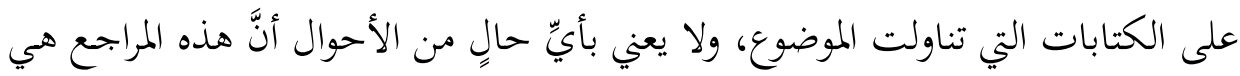

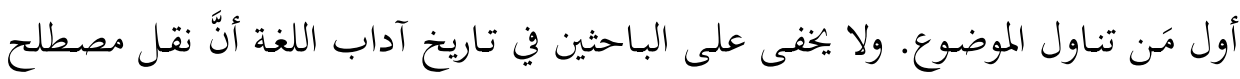

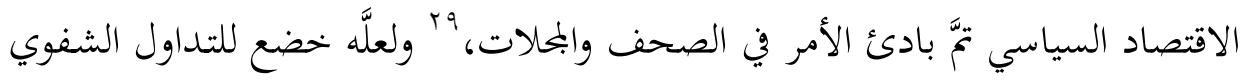

27 Hosseini, Hamid. Understanding the Market Mechanism before Adam Smith: Economic Thought in Medieval Islam, History of Political Economy, Vol. 27, No. 3, 1995, p. 541.

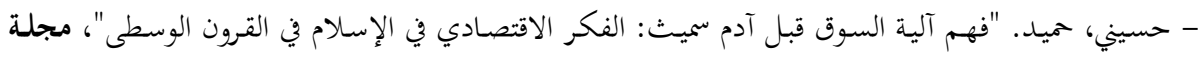

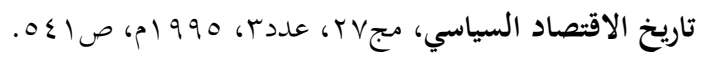

${ }^{28}$ Malinvaud, Edmond. Propos de circonstance sur les orientations de la discipline économique, Annales ESC, $45^{\mathrm{e}}$ année, ${ }^{\circ}{ }^{1}$, janvier-février 1990, pp. 115-116.

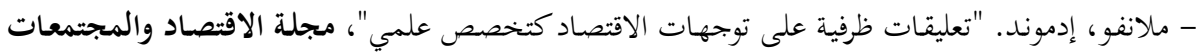

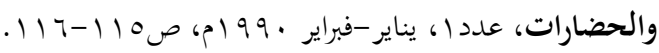

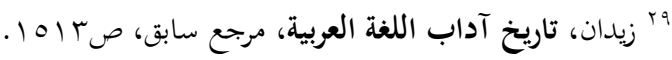


قبل الكتابي، وهي فرضية يصعب اختبارها علمياً في ظل شُحِّ المعلومات المتوفرة عن تلك الحقبة الزمانية.

\section{ثالثاً: نشأة مصطلح الاقتصاد السياسي في الأدبيات العربية}

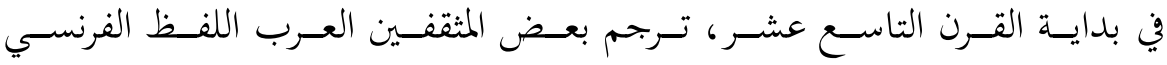

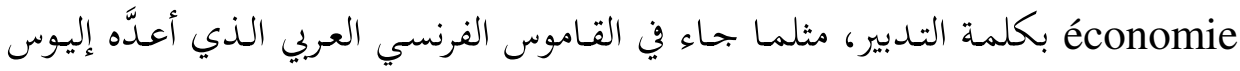

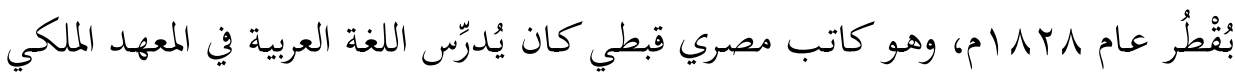

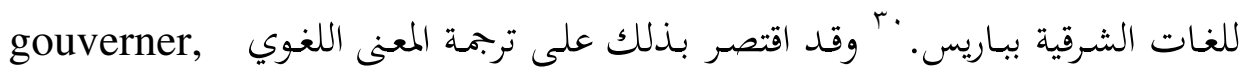
administrer

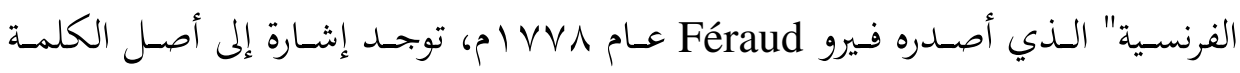

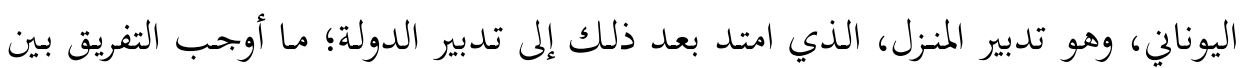

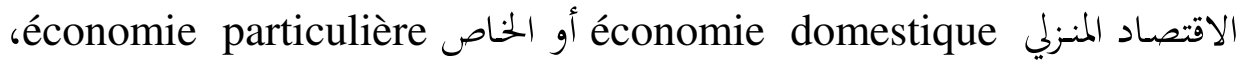

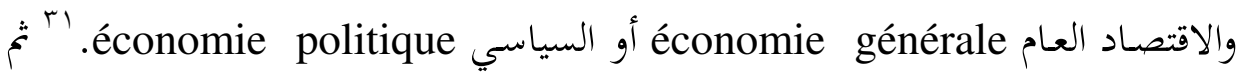

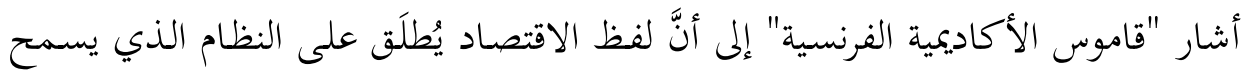

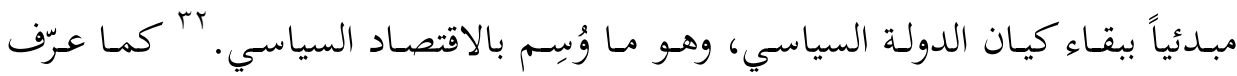

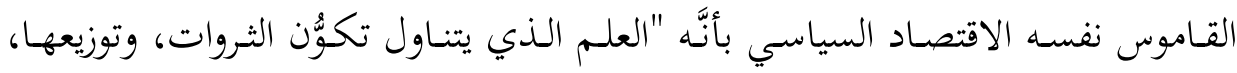

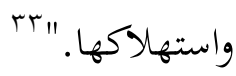

${ }^{30}$ Bochtor, Ellious. Dictionnaire français-arabe, revu et augmentée par Caussin de Perceval, Paris: Imprimerie de Firmain Didot, 1828, tome 1, p. 291.

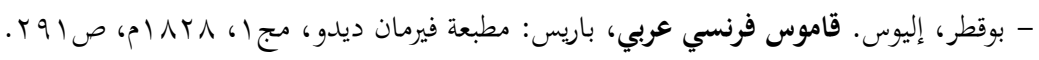

${ }^{31}$ Féraud, Jean-François. Dictionnaire critique de la langue française, Marseille: Jean Possy Père et Fils, tome second, 1787, p. 21.

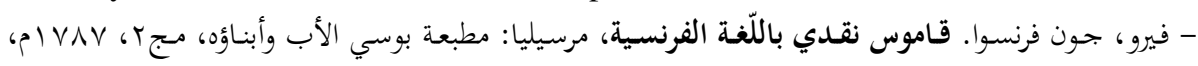

${ }^{32}$ Académie française. Dictionnaire de l'Académie française, Paris: Dabin, supplément, 1802, p. 521.

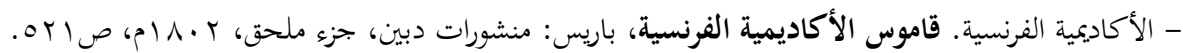

${ }^{33}$ Académie française. Dictionnaire de l'Académie française, Bruxelles: J. P. Méline, Librairie-éditeur, tome premier, 1802, p. 654. 
وفي كتابه "تخليص الإبريز في تلخيص باريز"، أشار رفاعة الطهطاوي إلى مـا كان

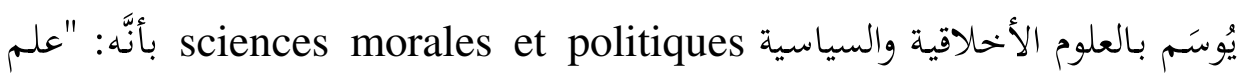

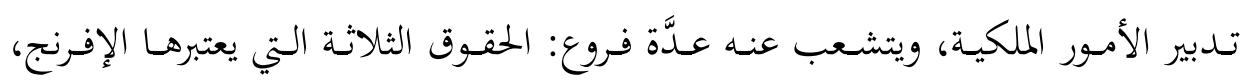

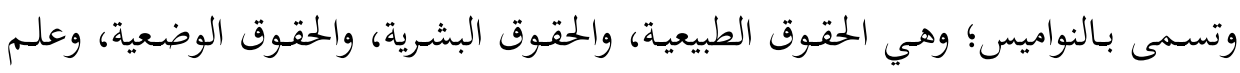

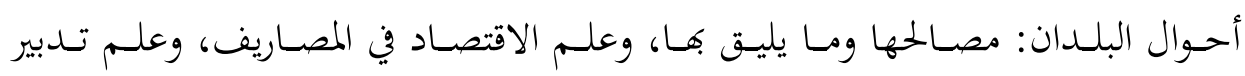

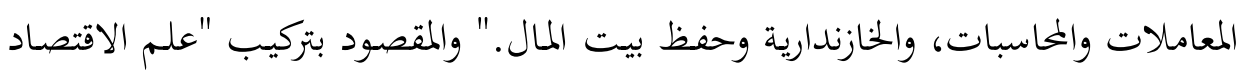
في المصاريف" هو علم الاقتصاد السياسي économie politique

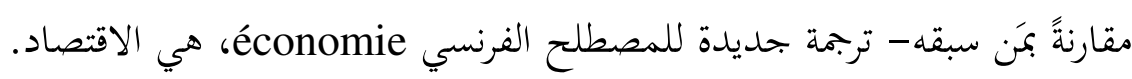
ولعـلَّ خير الدين التونسي هـو أول مَن استخدم باللغـة العربيـة مصطلح الاقتصاد

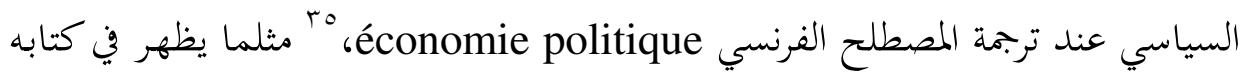

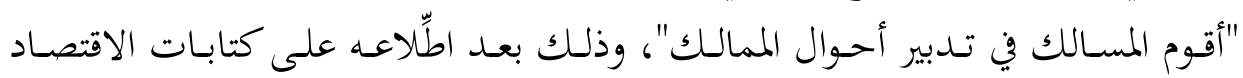

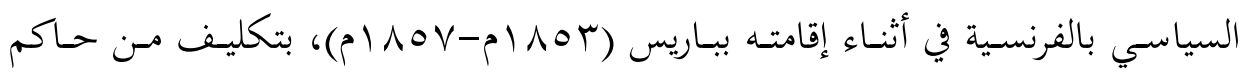
تونس آنذاك أحمد الباي.

وقد ذكر في معرض حديثه عن أهم ملامح المدنية الأوروبية أنَّ آدم سميث فاق أقرانه

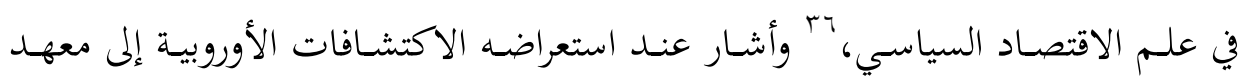
فرنسا الذي يضم جمعيات مـ كبار العلماء تسمى الأكاديميات، ومنها أكاديمية العلوم

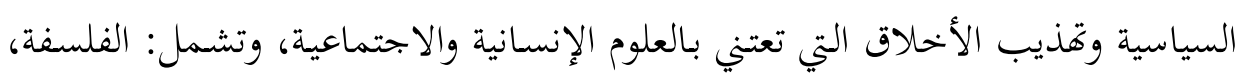

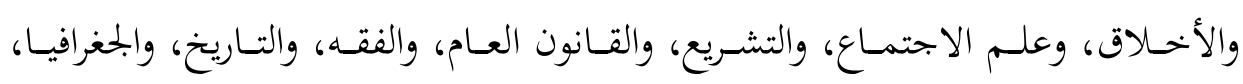

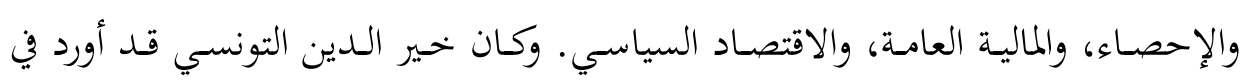

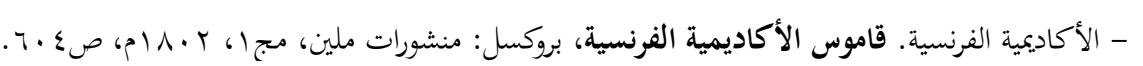

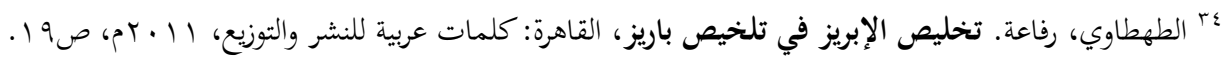

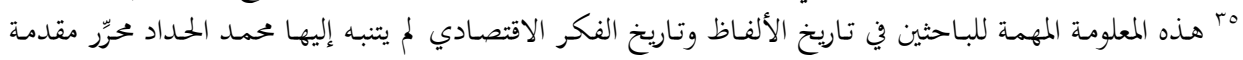

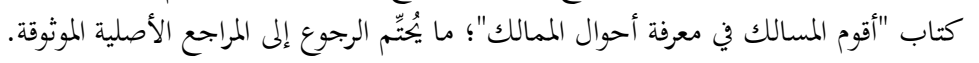

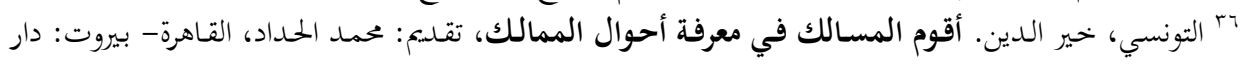

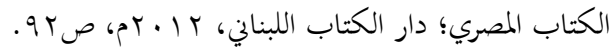


كتابه ما يأتي: "والإكونومي بولتيك؛ أي الاقتصاد السياسي". وهو ما يُظهِر -بما لا يدع بحالاً للشكدّا- ترجمته له من المصطلح الفرنسي économie politique. وأشار أيضاً إلى

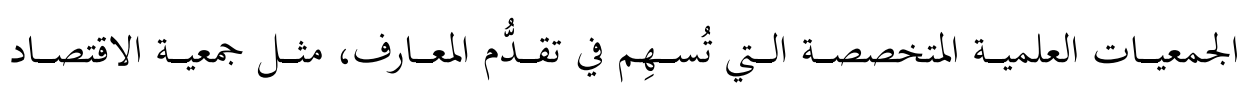

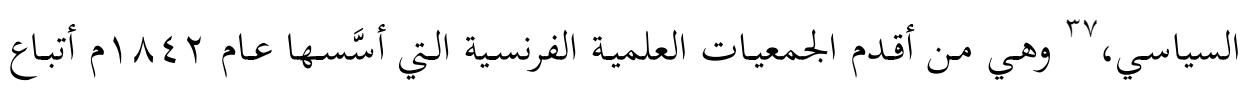

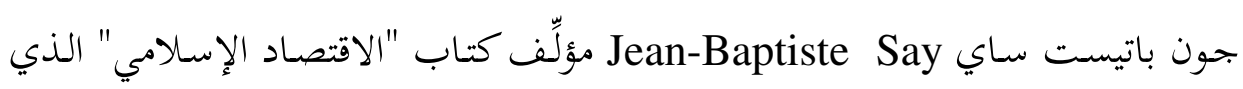

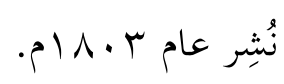

ويعزو البـاحثون في تاريخ آداب اللغـة العربيـة، وتـاريخ المطبوعـات العربيـة والـمُعَّبة،

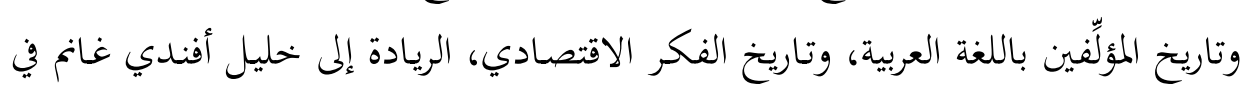

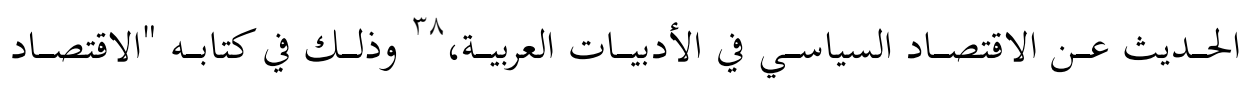

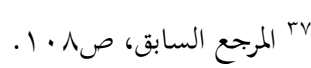

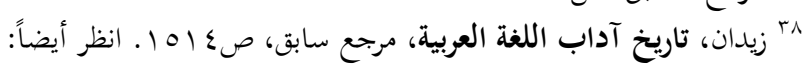

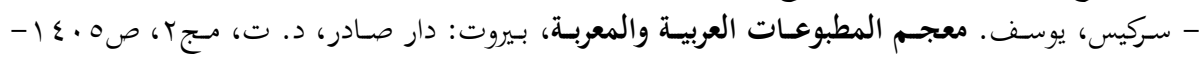

$$
\begin{aligned}
& \text {. } 1 \text {. } 7
\end{aligned}
$$

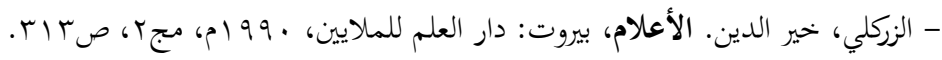

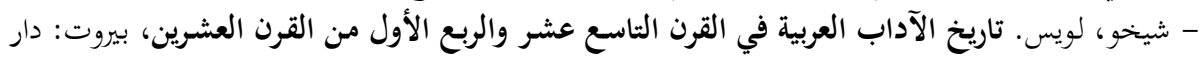

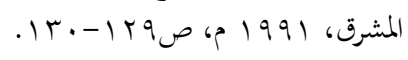

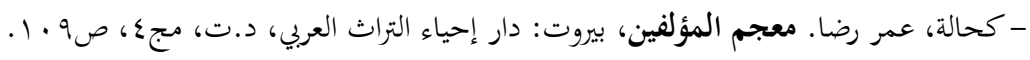

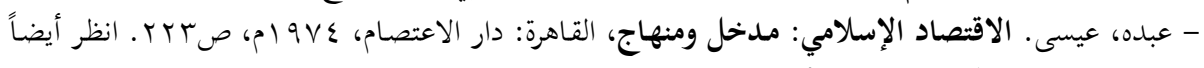

$$
\text { باللغتين الفرنسية والإنحليزية المراجع الآتية: }
$$

- O. O. Compte rendu du livre El-Iktissad-el-seyassi. Traité d'économie politique, par Khalil Ghanem, imprimerie du journal Asser-el-jedid, Alexandrie (Egypte), Journal des économistes - Revue de la science économique et de la statistique, $40^{\mathrm{e}}$ année de la fondation, $4^{\mathrm{e}}$ série, $4^{\mathrm{e}}$ année, tome quatorzième, Paris: Guillaumin et Ce éditeurs, avril- juin 1881, p. 315-316.

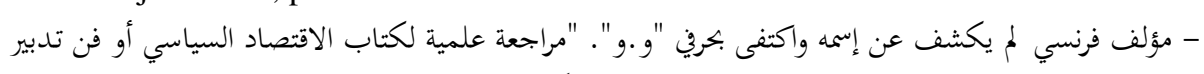

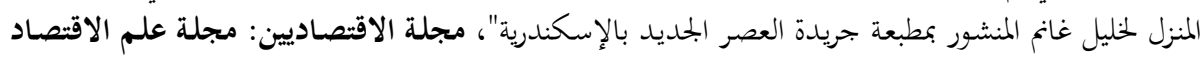

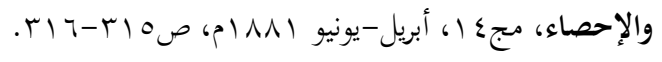

- Sharabi, Hisham. Arab Intellectuals and the West: the Formative Years, 1875-1914,

Baltimore and London: The Johns Hopkins, 1970, p. 81.

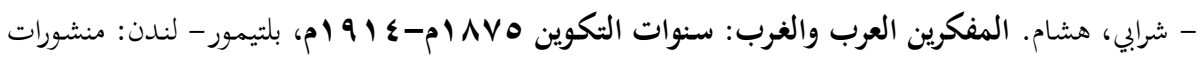

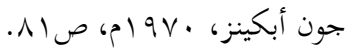




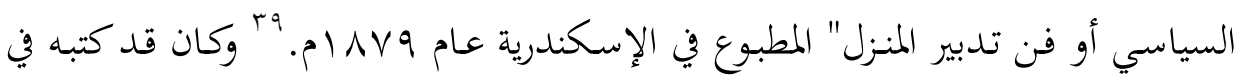

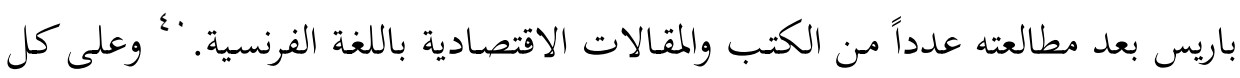

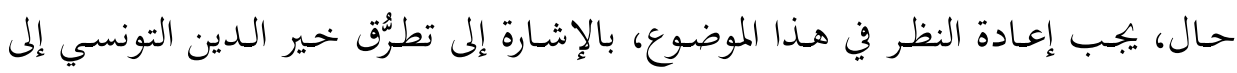

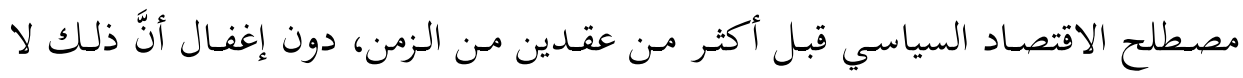

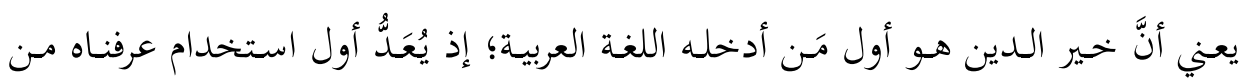
مراجع موثوقة، ولا يعني حتماً شهادة ميلاد للمصطلح.

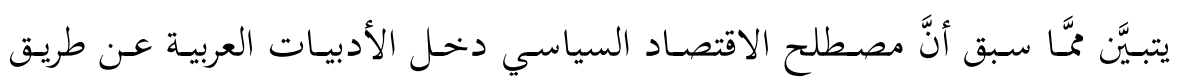

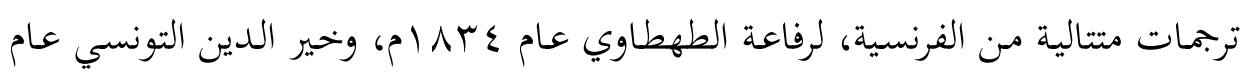

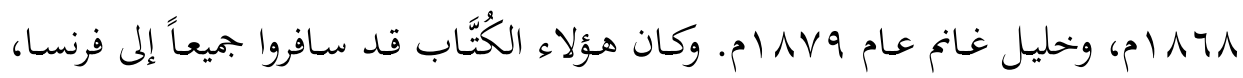

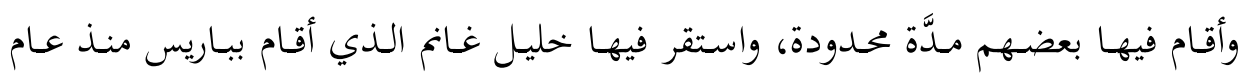

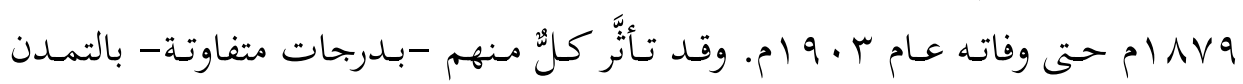

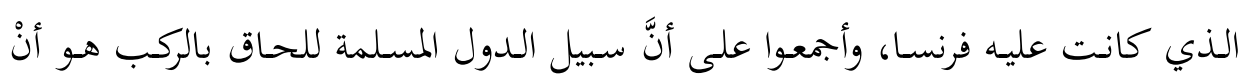
تحذو حذو النموذج الأوروبي في تلقي علم الاقتصاد السياسي وتدريسه.

- Zachs, Fruma and Halevi, Sharon. Gendering Culture in Greater Syria: Intellectuals and Ideology in the Late Ottoman Period, London - New York: I.B.Tauris, 2014, p. 87.

$$
\begin{aligned}
& \text { - زاشس، فروما وحليفي، شارون. ثقافة التكافؤ بين الجنسين في سوريا الكبرى: المثقفون والأيديولوجيا في }
\end{aligned}
$$

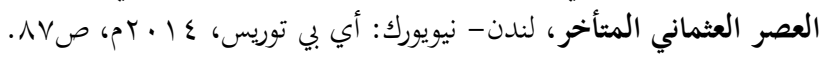

- Islahi, Abdul Azim. Economic Thinking of Arab Muslim Writers during the Nineteenth Century, London: Macmillan Palgrave, 2015, p. 25.

- إصلاحي، عبد العظيم. الفكر الاقتصـادي للكتاب العرب والمسلمين إبان القرن التاسع عشر، لندن:

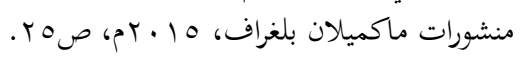

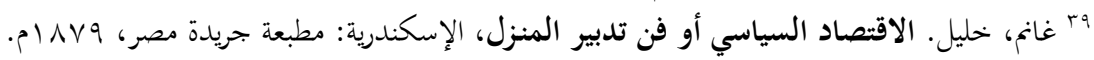

${ }^{40}$ O. O. Compte rendu du livre El-Iktissad-el-seyassi. Traité d'économie politique, par Khalil Ghanem, Journal des économistes - Revue de la science économique et de la statistique, avril- juin 1881, p. 316.

- "و. و". مراجعـة علميـة لكتـاب الاقتصـاد السياسـي أو فـن تـدبير المنـزل لخليـل غـانم، مرجع سـابق، 
ومنذ هاية القرن التاسع عشر، ابتهت النخب الفكرية العربية إلى استخدام مصطلح

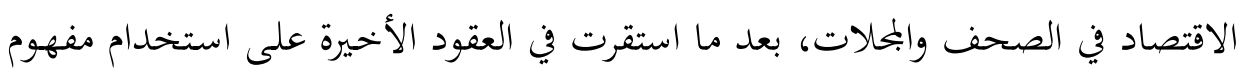

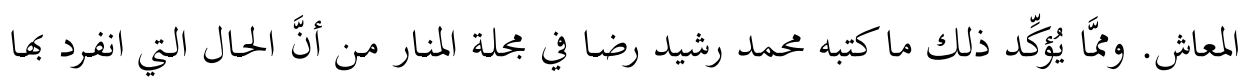

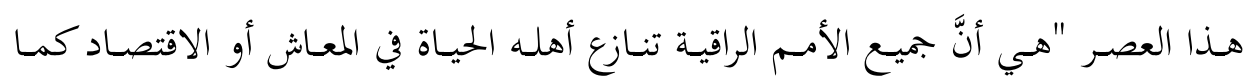

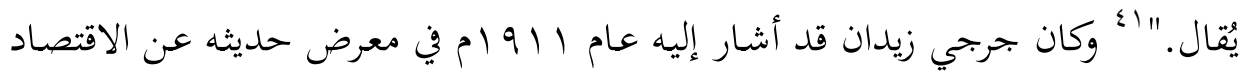

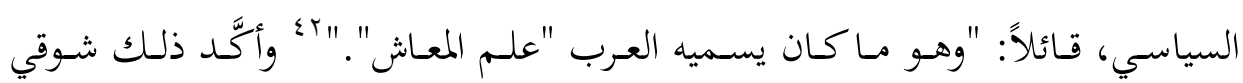

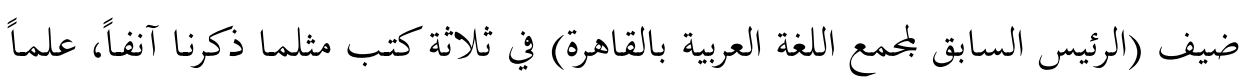

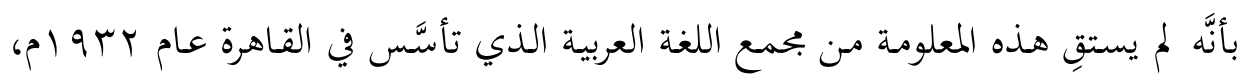

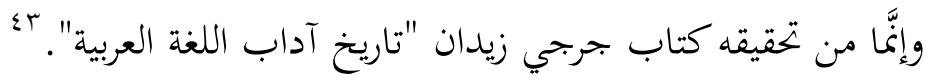

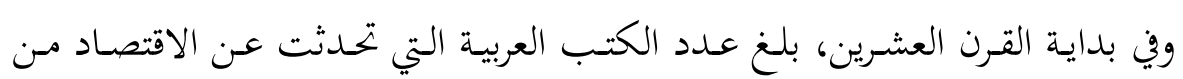

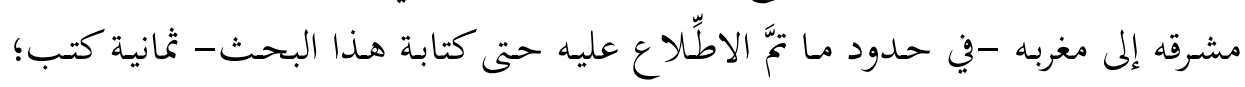

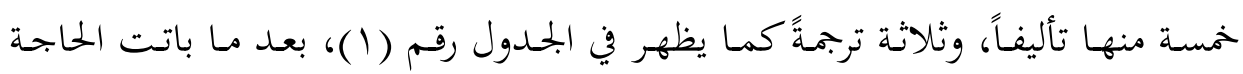

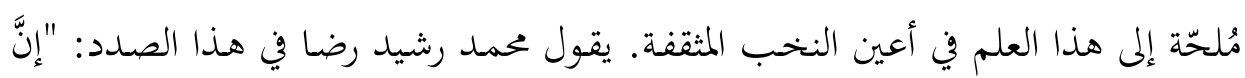

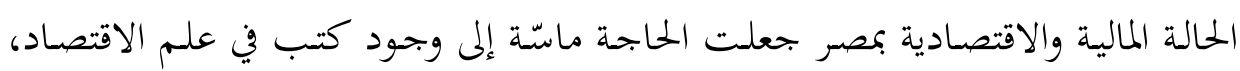

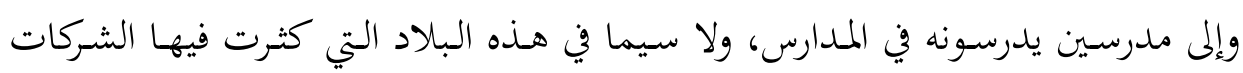

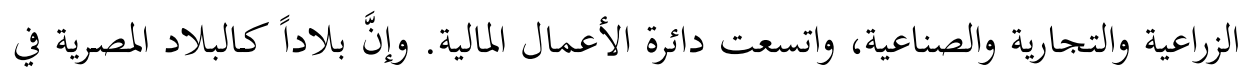

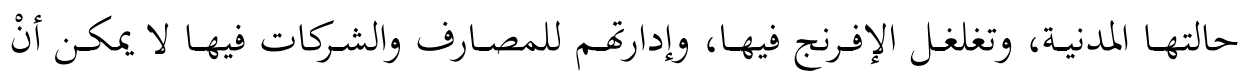

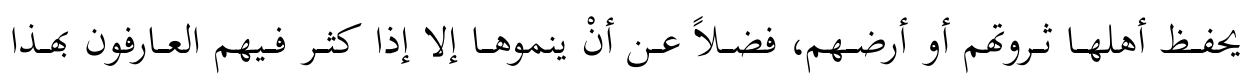

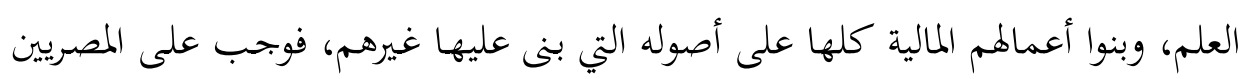

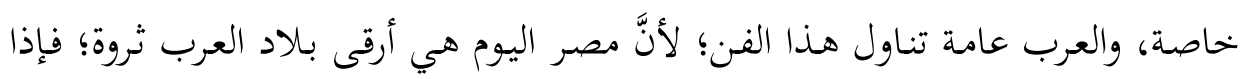
ارتقى هذا العلم فيها يكون ذلك مقدمة لارتقائه في غيرها."

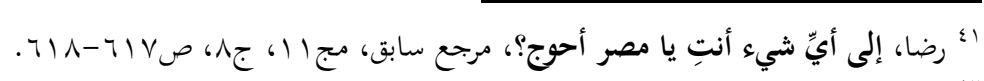

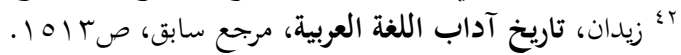

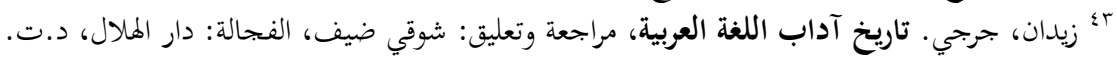

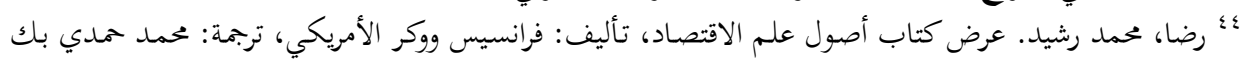

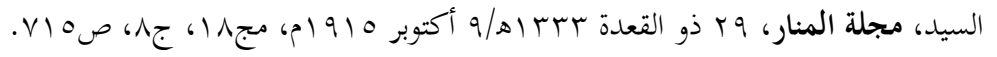


الجــدول (1): مؤلفـات الاقتصـاد باللغـة العربيـة منـذ هايـة القـرن التاسع عشـر حتى

\begin{tabular}{|c|c|c|c|c|}
\hline مكان & سنة النشر & ماهية & العنوان & المؤلِّف \\
\hline 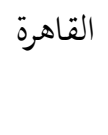 & plsvq & تأليف & الاقتصاد السياسي أو فن & خليل غانم \\
\hline 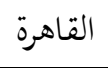 & plᄉᄉ & تأليف & أصول الاقتصاد السياسي & رفلة جرجس \\
\hline 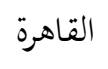 & م) 1190 & ترجمة & الاقتصاد السياسي & وليام جفونس \\
\hline الجزائر & $p 19 \cdot \varepsilon$ & ت ت تأليف & المرصاد في مسائل الاقتصاد & عبدالقادر المجاوي وعمر \\
\hline 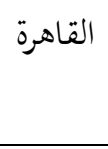 & $\begin{array}{l}-p 19 \cdot 1 \\
p 1911\end{array}$ & تأليف & مبادئ علم الاقتصاد & حسين محمد فهمي \\
\hline حمص & p191r & تأليف & حياة البلاد في علم الاقتصاد & رفيق رزق سلوم \\
\hline 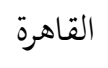 & rاp & ترجمة & الموجز في علم الاقتصاد & بول لروا بوليو \\
\hline القاهرة & p1910 & ترجمة & أصول علم الاقتصاد & فرانسيس ووكر \\
\hline
\end{tabular}

ويُظهِرِ الشكل رقم (1) - بنـاءً على بيانات الملحق - عدد مرات استخدام مصطلح الاقتصاد في عناوين المقالات التي نُشِرت في بحلة المشرق التي أسَّسها لويس شيخو عام

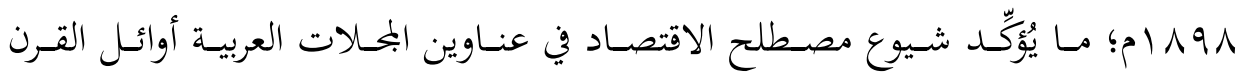

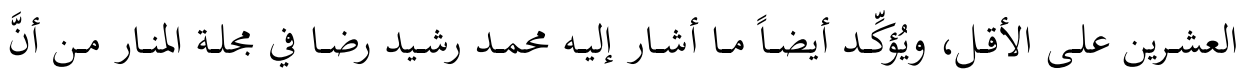

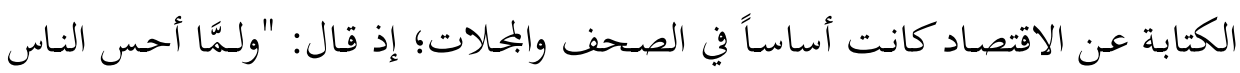
بالحاجـة إلى هـا العلم في السـنين الأخـيرة كتـب فيـه بعض الكـاتبين مقـالات في الجرائد

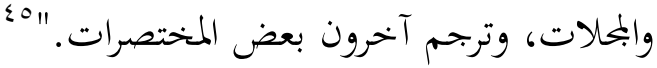


الشكل ( (1): رسم بياني يُوضِّح عدد مرات استخدام مصطلح الاقتصاد في عناوين المقالات التي نُشِرت في مجلة المشرق.

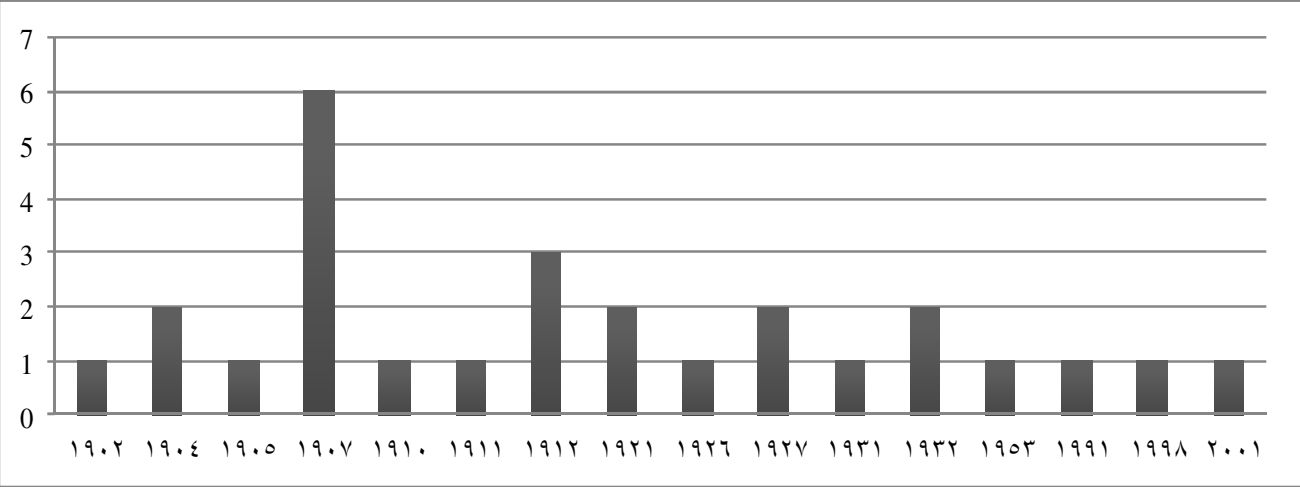

المصدر : من إعداد الباحث

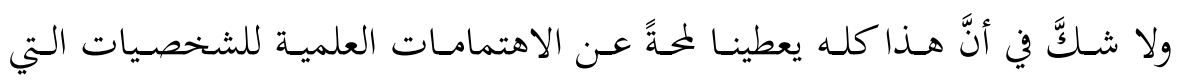
تصدّت لمهمة الكتابة عن الاقتصاد في العالم العربي منذ هاية القرن التاسع عشر وبداية

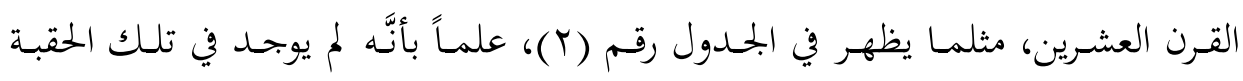

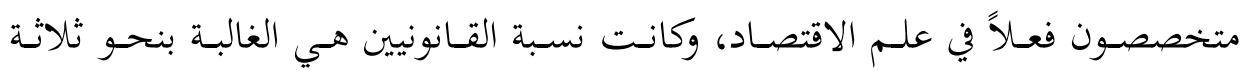

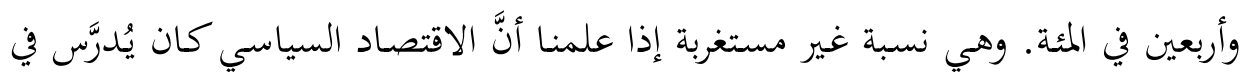

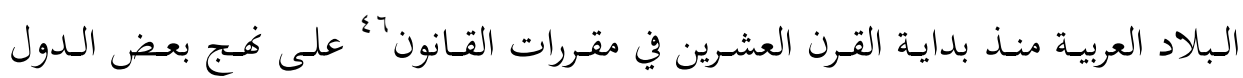
الأوروبية. البادو العربية

ب؛ زرهوني، الطاهر. التعليم في الجزائر قبل وبعد الاستقلال، الجزائر: المؤسسة الوطنية للفنون المطبعية، ب99 (م)،

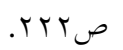

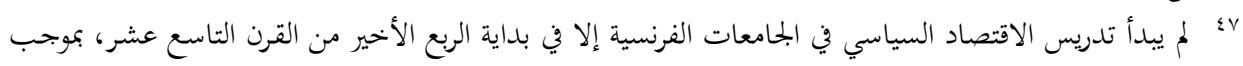

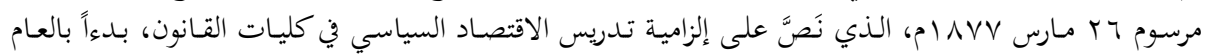
الثاني لليسانس أو البكالوريوس. انظر :

- Le Van-Lemesle, Lucette. L'économie politique à la conquête d'une légitimité, 1896-1937, Actes de la recherche en sciences sociales, 1983, n47-48, p. 113.

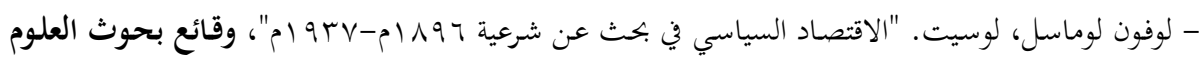

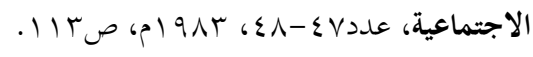


الجحدول (r): التخصص العلمي للنخبة العربية التي كتبت عن الاقتصاد بين عامي

\begin{tabular}{|c|c|c|}
\hline مكان الترجمة أو التأليف & المهنة & المؤلِّف \\
\hline 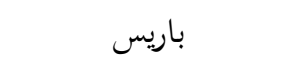 & أديب وصحفي & خليل غانم \\
\hline القاهرة & مترجم & رفلة جرجس \\
\hline الجزائر & فقيه وأديب & عبدالقادر المحاوي \\
\hline الجزائر & قانوني وفقيه & عمر بريهمات \\
\hline القاهرة & قانوني ومحامٍ & حسين محمد فهمي \\
\hline إستانبول & قانوين وأديب & رفيق رزق سلوم \\
\hline القاهرة & قاضٍ & محمد حمدي بك \\
\hline
\end{tabular}

\section{رابعاً: نشأة مصطلح الاقتصاد السياسي في الأدبيات التركية العثمانية}

مثلما هو الحال في الأدبيات العربية، دخل مصطلح الاقتصاد السياسي في الأدبيات التركية العثمانية عن طريق ترجمة المصطلح الفرنسي économie politique، بدءاً بعام • ب ا ام؛ لأنَّ الفرنسية كانت في تركيا هي اللغة المشتركة بين الأكاديميين، وأكثر اللغات الأجنبية شعبية في أوساط المفكرين. يضاف إلى ذلك اعتماد العثمانين -أيام الإصلاح

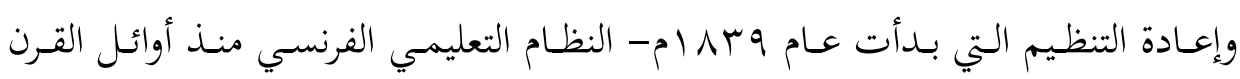

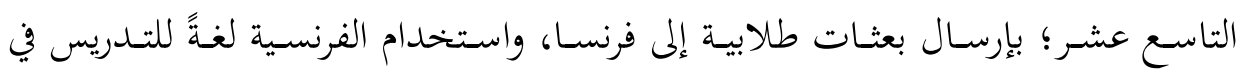
المدارس العليا، وبناء مدرسةِ بباريس للطلبة الأتراك عام NoV ا م، وثانويةٍ فرنسية في حي

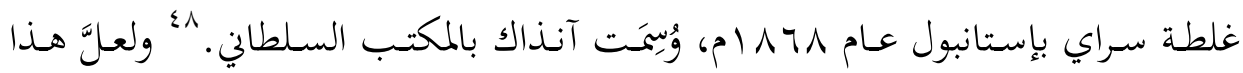

${ }^{48}$ Georgeon, François. La formation des élites à la fin de l'Empire ottoman: le cas de Galatasaray, Revue du monde musulman et de la Méditerranée, 1994, Volume 72, Numéro 1, pp. 15-25.

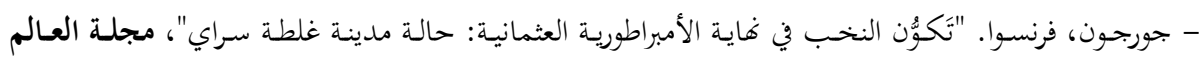

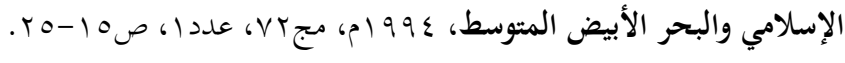




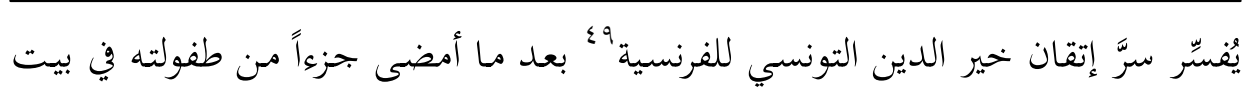

$$
\text { نقيب الأشراف تحسين بك بإستانبول. . }
$$

وإذا كانت هـذه الأدبيـات قـ كُّبــت باللغة التركيـة العثمانيـة في أثنـاء حكـم الدولة

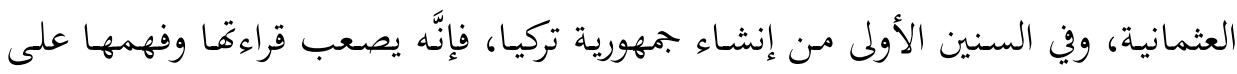

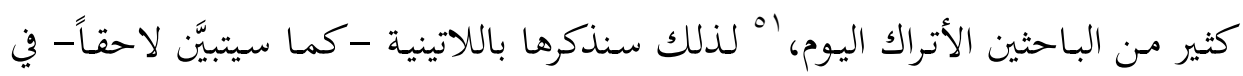

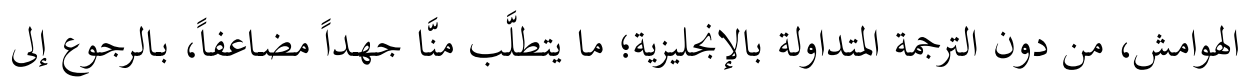
المراجع الأصلية كلَّما تيسَّر ذلك، وترجمتها من اللغة التركية إلى العربية.

وفي هذا السياق، أشـار باحثون عن أدبيات الاقتصاد السياسي إلى مخطوط بجهول

المؤلِّف في المكتبـة الوطنيـة النمســاوية Nationalbibliothek Österreichische،

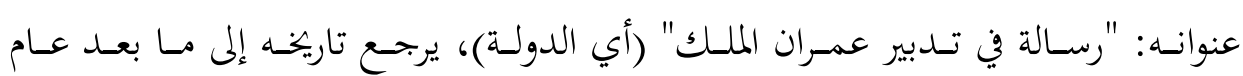

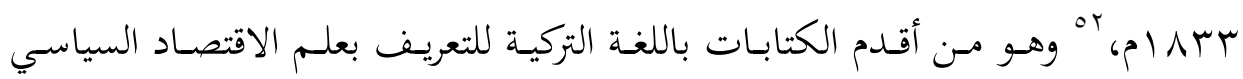
الذي كان متداولاً آنذاك في الأدبيات الأوروبية بلغات عدَّة.

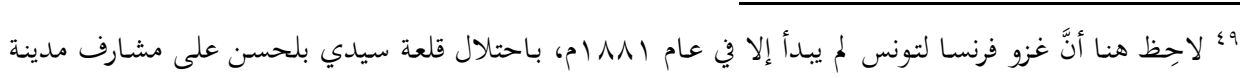
تونس.

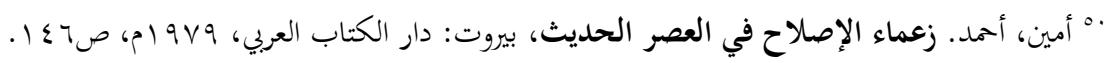

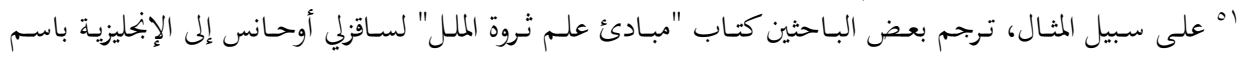

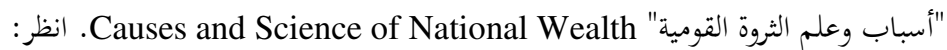

- Özveren, Yüp and Kaya, Alp Yücel. Adaptation as an Original Genre in the

Ottoman Economic Thought of the Nineteenth Century, Paper presented to International Conference 'Translations of economic texts into and from European languages', University of Pisa, 12-14 September 2013.

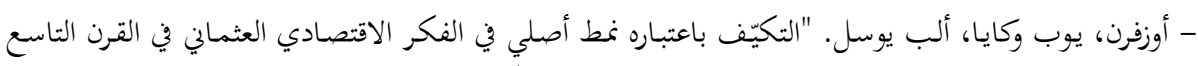

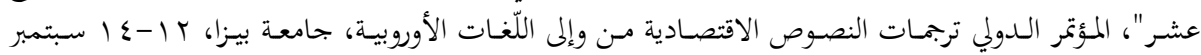

${ }^{52}$ Badem, Candan. The Ottoman Crimean War (1853-1856), Leiden: Brill, 2010, p. 289; Koloğlu, Orhan. The Ottoman Press during the First Phase of Transition to Capitalism (1821-1875), In Gisela Procházka-Eisl, Martin Strohmeier (editors). The Economy as an Issue in the Middle Eastern Press, Münster: LIT Verlag Münster, 2008, p. 109; Kilinçoğlu, Deniz T. Economics and Capitalism in the Ottoman Empire, London: Routledge, 2015, p. 26. 


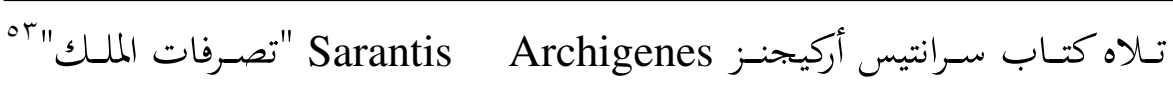
Tasarrufat-1 Mülkiye

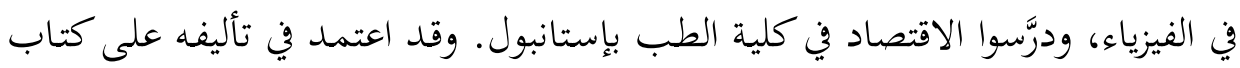

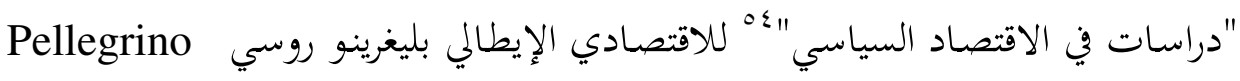
Rossi

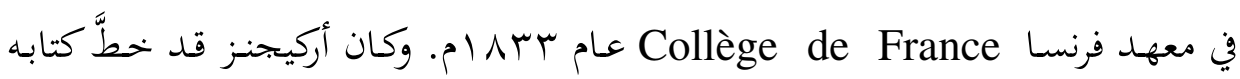
بالفرنسية، وكلَّف الشاعر اليوناني ألكسوندروس سوتسو Alexandros Sutso بترجمته

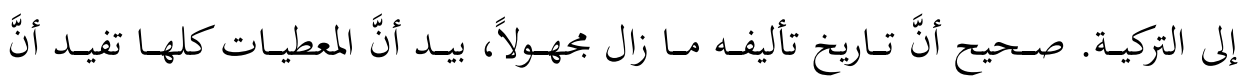

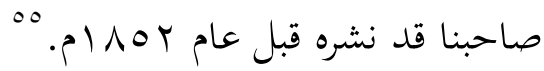

Catéchisme تم تبعته ترجمة تركية لكتاب الاقتصادي الفرنسي جون باتيست ساي d'économie politique

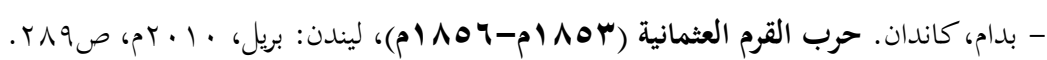

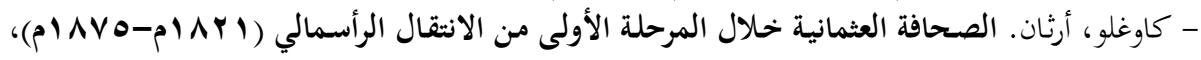

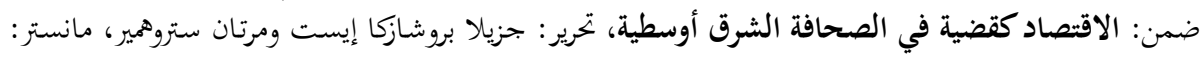

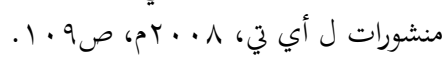

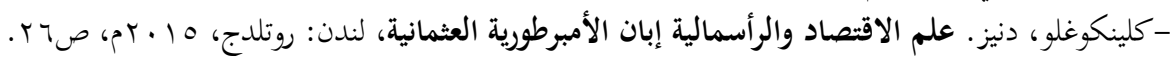

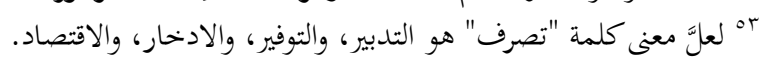

${ }^{54}$ Rossi, Pellegrino. Cours d'économie politique, Paris: Joubert, 1840.

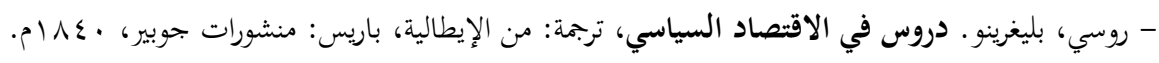

${ }^{55}$ Badem, Candan. Op. cit., 2010, p. 289; Kilinçoğlu, Deniz T. Op. cit., p. 27.

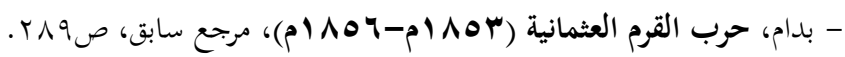

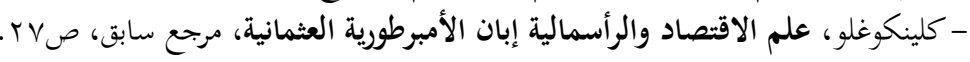

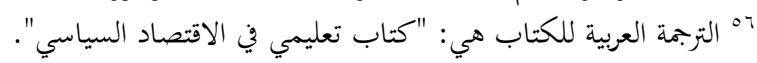

${ }^{57}$ Bulbul, Yasar. Op. cit., p. 5; Özvar, Erol. Economics History in Turkey, In Francesco Ammannati (editor). Where is Economics History Going? Methods and Prospects from the $13^{\text {th }}$ to the $18^{\text {th }}$ Centuries, Firenze: Firenze University Press, 2011, p. 101.

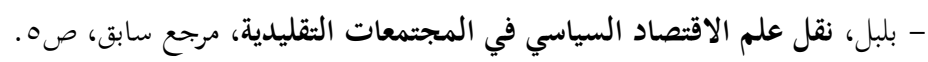

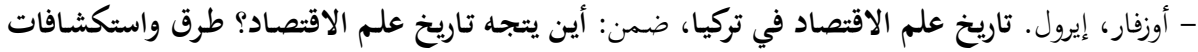

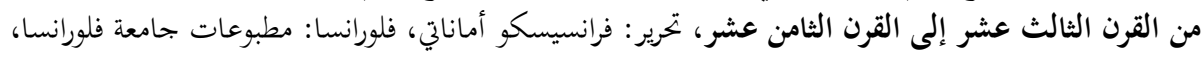


معروف في عهد الخلافة العثمانية بحسب ما ذكر بعض العلماء الأتراك، أمثال: المُؤرِّخ

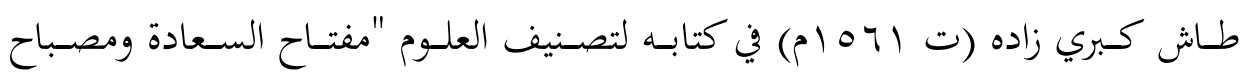

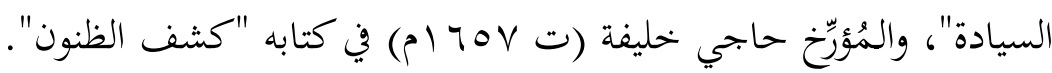

وكان المستشـرق البريطاني تشـارلز ويلز قـد نشـر كتابـاً بالتركيـة عنوانه "علم تـدبير

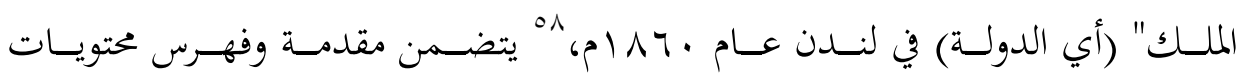

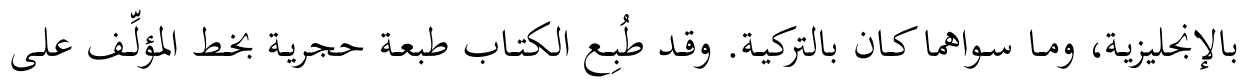
الأرجح.

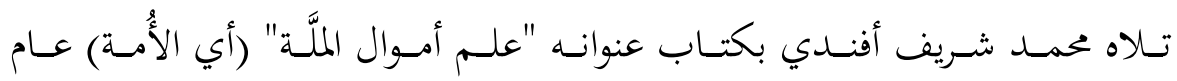

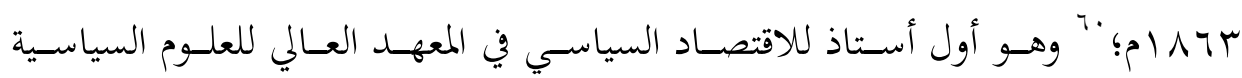
Mekteb-i Mülkiye

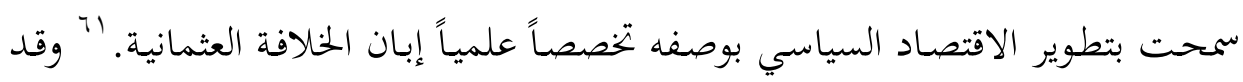

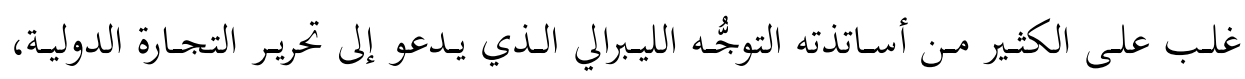
والإعفاء من الرسوم الجمركية.

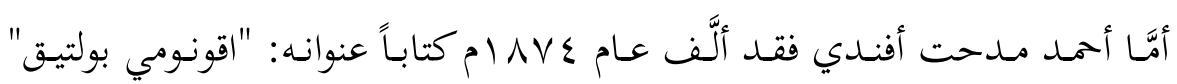

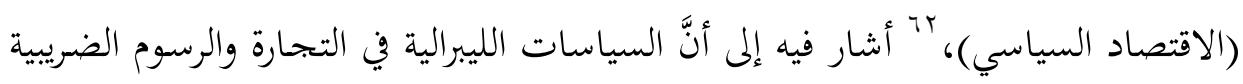

${ }^{58}$ Wells, Charles. Ilm Tedbir Milk, London: Williams and Norgate, 1860.

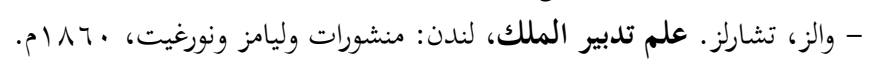

${ }^{59}$ Kilinçoğlu, Deniz T. Op. cit., p. 39.

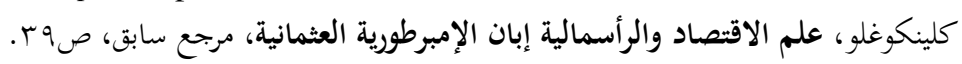

${ }^{60}$ Şerif, Mehmed. Illm-i Emval-i Milliye, İstanbul: Tab'hane-i Âmire Litoğrafya Destgahı, 1863.

$$
\text { - شريف، محمد. علم أموال الملّة، إستانبول: المطبعة الأميرية، بآملام. }
$$

${ }^{61}$ Özveren, Eyüp. Turkey and the Turkic Linguistic Zone: The Case that doesn't Quite Fit, Vincent Barnett (editor). Routledge Handbook of the History of Global Economic Thought, New York: Routledge, 2015, p. 182.

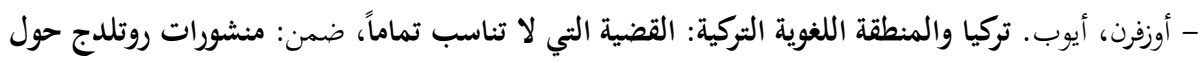

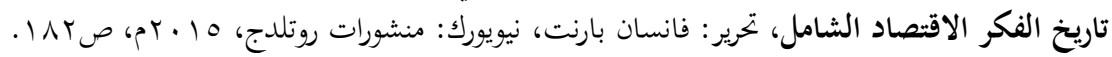

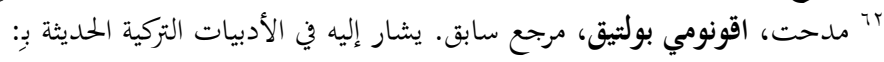




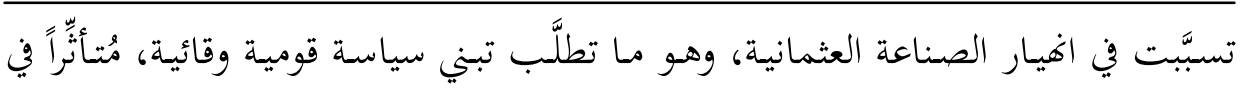

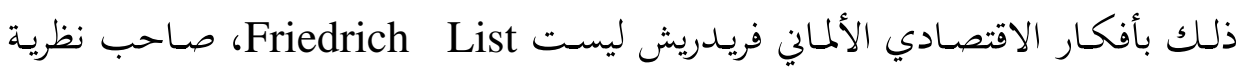

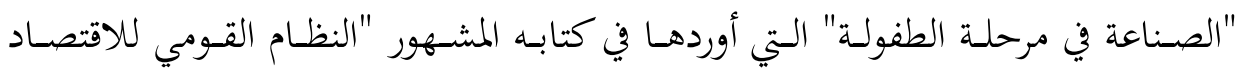

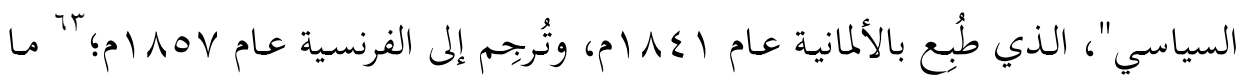

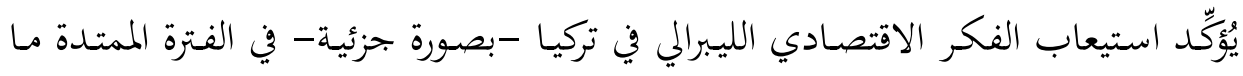
بين ثلاثينيات القرن التاسع عشر وستيناته.

تــلاه سـاقزلي أوحـانس باشـا بكتـاب "مبـادئ علـم ثـروة الملـل (أو الأمـم) عـام

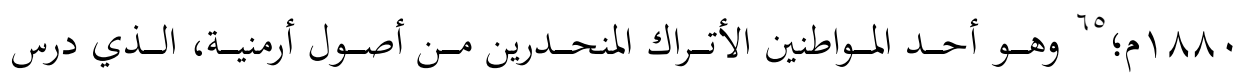

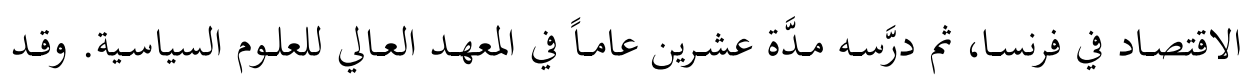

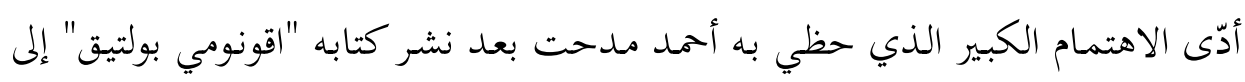

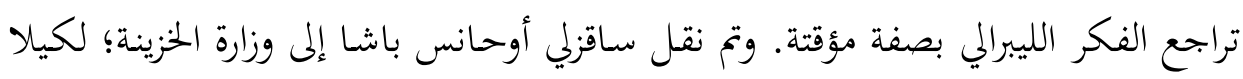
يُؤُّرّ في طلاب المعهد العالي للعلوم السياسية.

- Midhat, Ahmet. Ekonomi politik, Istanbul: Kırk Anbar Matbaası, 1879.

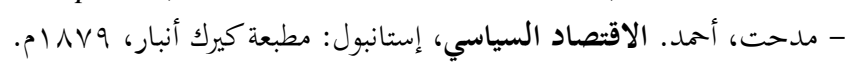

${ }^{63}$ List, Friedrich. Système national d'économie politique, Paris: Edition de Henri Richelot, 1857.

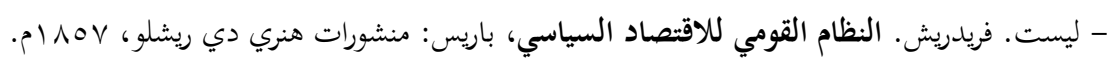

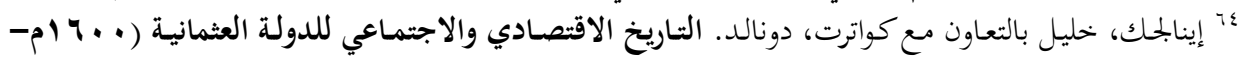

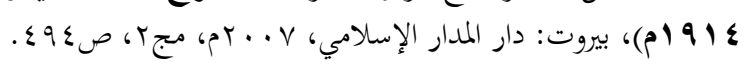

65 Ohannes, Sakızl. Mebadi-i ilm-i servet-i milel, Dersaadet [Istanbul]: Mihran Matbaası, 1297 (1880).

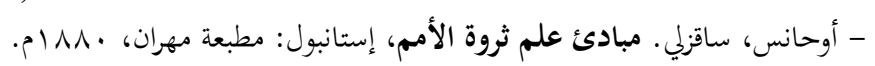

${ }^{66}$ Psalidopoulos, Michalis M. and Theocarakis, Nicholas J. The dissemination of economic thought in South-Eastern Europe in the nineteenth century, in Heinz-Dieter Kurz, Tamotsu Nishizawa, Keith Tribe (editors). The Dissemination of Economic Ideas, Cheltenham: Edward Elgar, 2011, pp. 164-165.

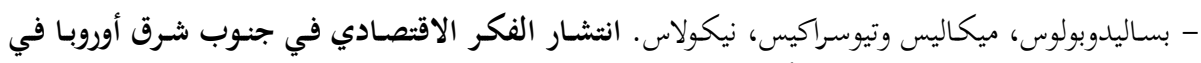

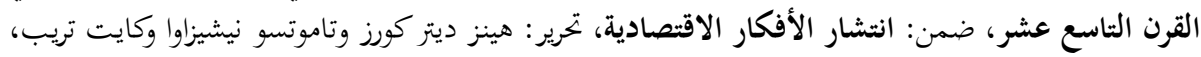




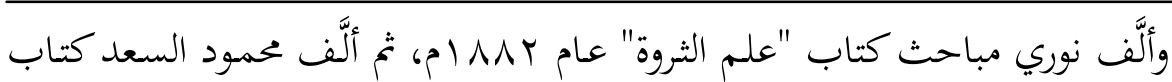

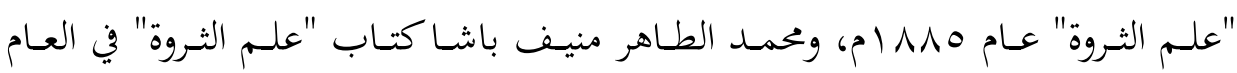

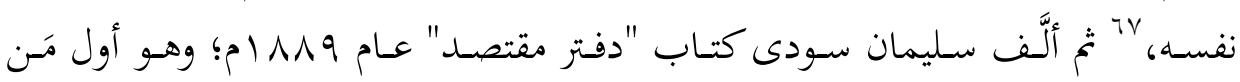

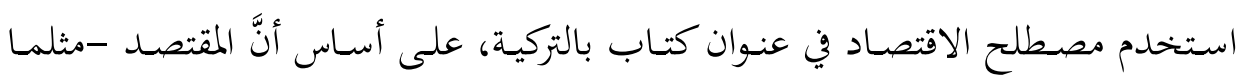

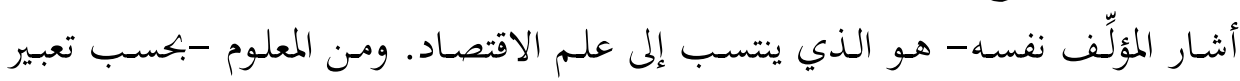
المؤلِّف- أنَّ كلمة الاقتصاد تعني لغةً العدل، واصطلاحاً حفظ الأموال وحمايتها، وحسن بلّن

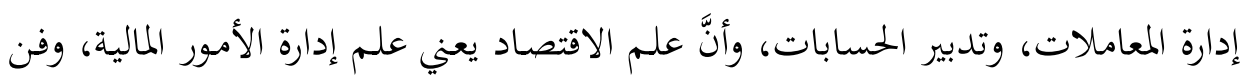

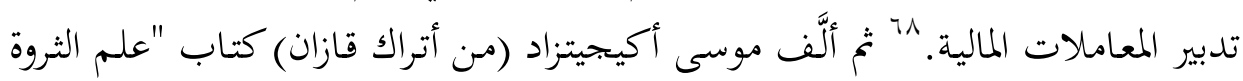

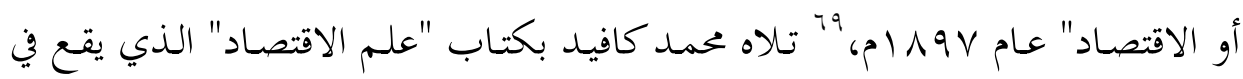

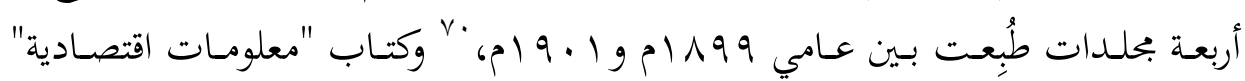

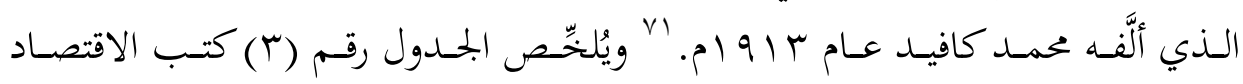

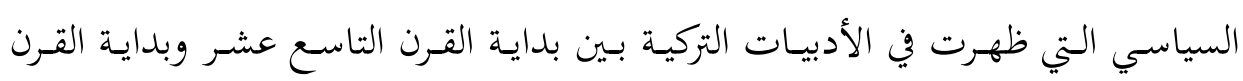
العشرين.

ممَّا تقدَّم بحد أنَّ ترجمة مصطلح الاقتصاد السياسي إلى التركية كانت نتاج التأثنّ ببريق

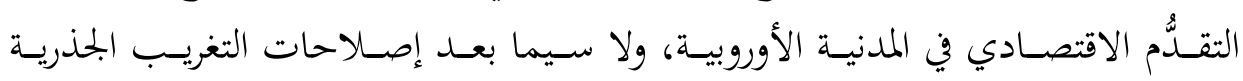

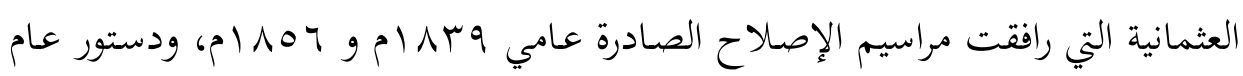
1 NVT

${ }^{67}$ Münif, Mehmed Tahir. İlm-i Servet, İstanbul: Mekteb-i Sanayi Matbaası, 1302 (1885).

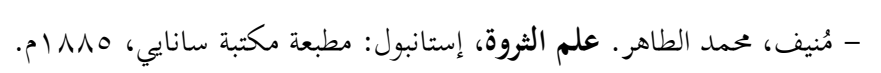

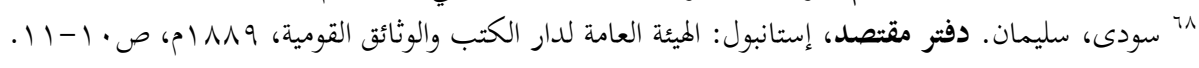

${ }^{69}$ Akyiğitzade, Musa. Illm-i Servet Veyahud Illm-i İktisad, Istanbul: Mekteb-i Harbiye Matbaası, 1314 (1897).

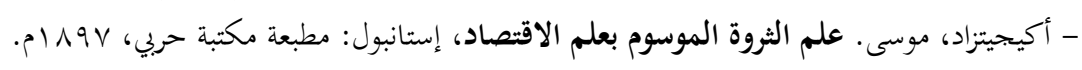

${ }^{70}$ Cavid, Mehmed. İlm-i iktisad, İstanbul: Matbaa-i Amire, 1899-1901.

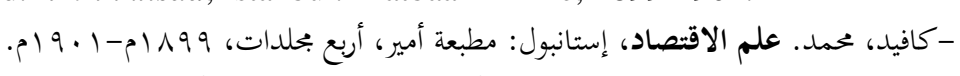

${ }^{71}$ Cavid, Mehmed. Malumat-ı İktisadiye, Istanbul: İlyas Matbaas1, 1913. 


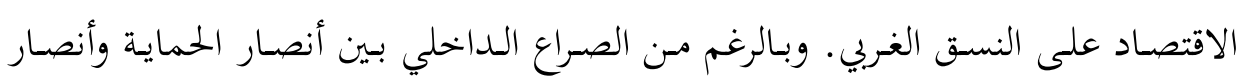

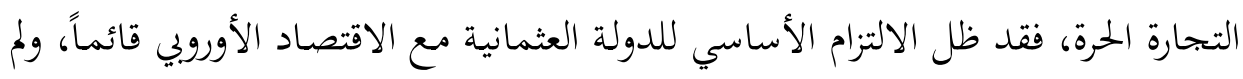

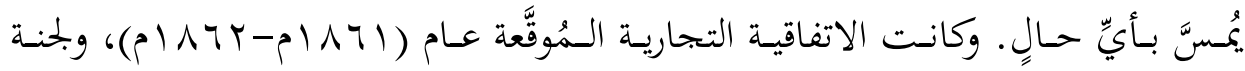

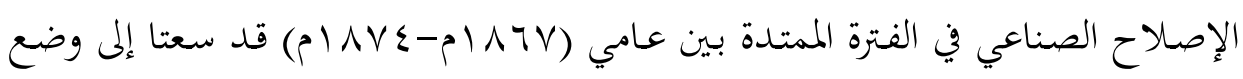

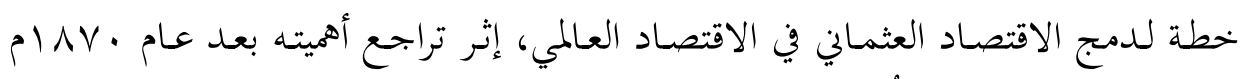

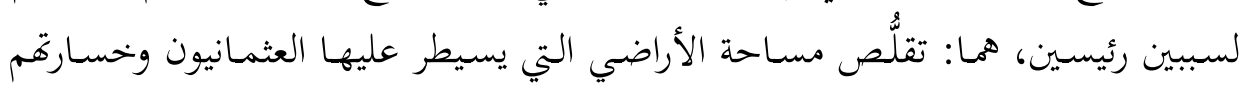

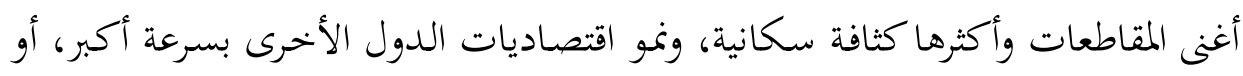
خضوعها للمصالح الاقتصادية الأوروبية. الجمدول (؟r): مؤلفات الاقتصاد السياسي باللغة التركية العثمانية المنشورة في الفترة

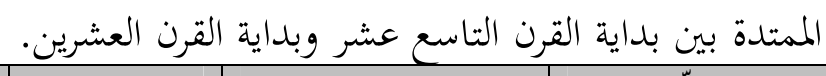

\begin{tabular}{|c|c|c|c|c|}
\hline مكان النشر & سنة النشر & ماهية الكتاب & العنوان & المؤلِّف \\
\hline إستانبول & بعد سنة & تخطوط & رسالة في تدبير عمران & بجهول \\
\hline إستانبول & plnot & ترجمة & علم تدبير المنزل & جون باتيست ساي \\
\hline ل ل لندن & plᄉt. & تأليف & علم تدبير الملك & تشارلز ويلز \\
\hline إستانبول & & تأليف & علم أموال الملَّة & محمد شريف أفندي \\
\hline إستانبول & plAvE & تأليف & اقونومي بوليتيك & أحمد مدحت أفندي \\
\hline إستانبول & plu. & تأليف & مبادئ علم ثروة الملل & ساقزلي أوحانس \\
\hline إستانبول & plNAr & تأليف & علم الثروة & نوري مباحث \\
\hline إستانبول & pl/10 & تأليف & علم الثروة & محمود السعد \\
\hline إستانبول & pl/10 & تأليف & علم الثروة & محمد الطاهر منيف \\
\hline
\end{tabular}

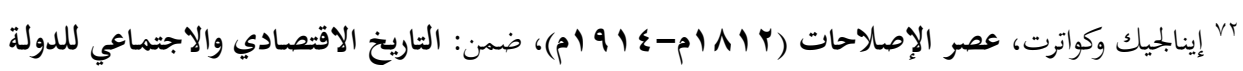

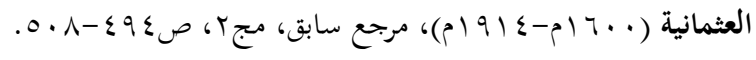




\begin{tabular}{|c|c|c|c|c|}
\hline إستانبول & plᄉᄉq & تأليف & دفتر مقتصد & سليمان سودى \\
\hline إستانبول & p $1 \wedge 9 \vee$ & تأليف & علم الثروة أو الاقتصاد & موسى أكيجيتزاد \\
\hline إستانبول & $\begin{array}{l}-p 1199 \\
p 19.1\end{array}$ & تأليف & علم الاقتصاد & محمد كافيد \\
\hline إستانبول & r & تأليف & معلومات اقتصادية & محمد كافيد \\
\hline
\end{tabular}

\section{خامساً: نشأة مصطلح الاقتصاد السياسي في الأدبيات الأُردية}

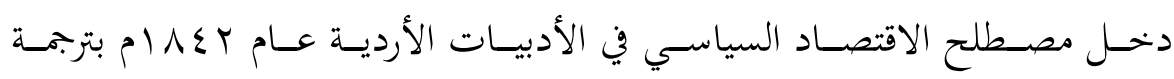

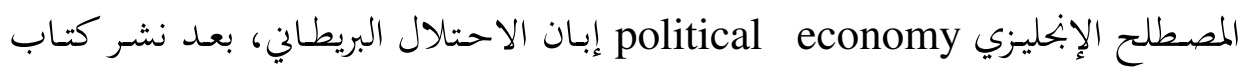

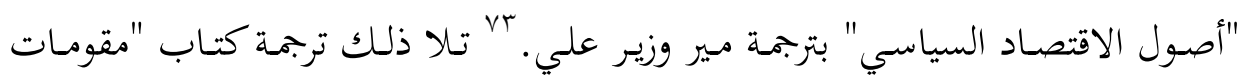
السياسة الاقتصادية" للاقتصادي الأمريكي فرانسيس ويلاند Francis Wayland تحت

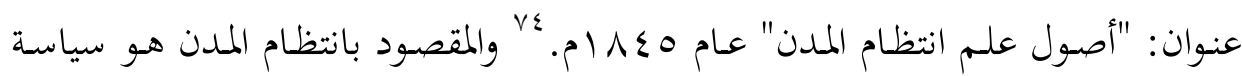

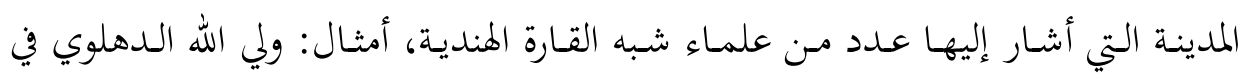

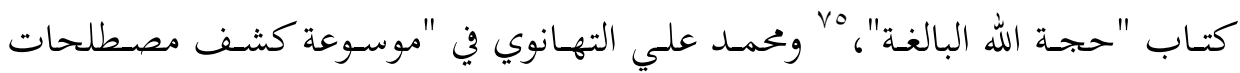

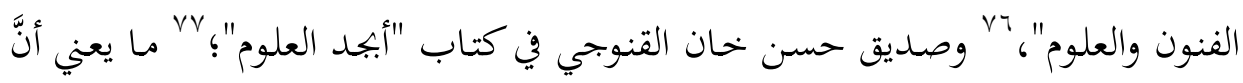

${ }^{73}$ Ali, Mir Vazir. Usool Political Economy, Delhi: Urdu Akhbar Press, 1842.

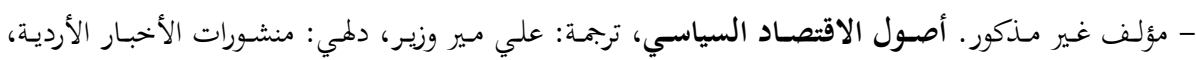
. $) \wedge \leqslant r$

${ }^{74}$ Wayland, Francis. The Elements of Political Economy, New York: Leavitt, Lord \& Co., 1837, translated to Urdu by Pandit Dharam Narayan, Usul-i 'Ilm-i Intizam-i Mudun, Dihli: Anjuman-i Isha'at-i 'Ulum-i Mufidah, 1845.

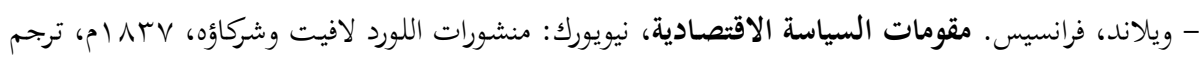

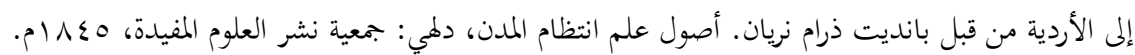

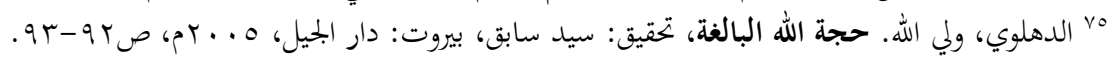

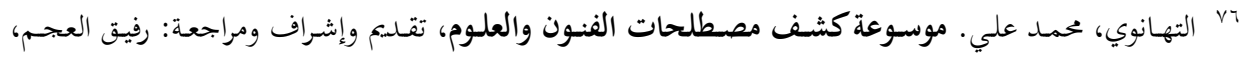

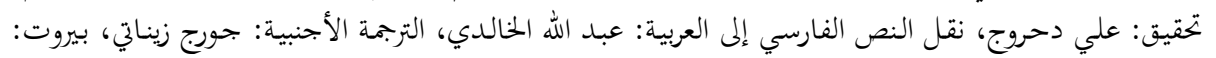

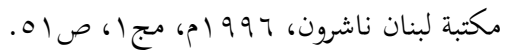

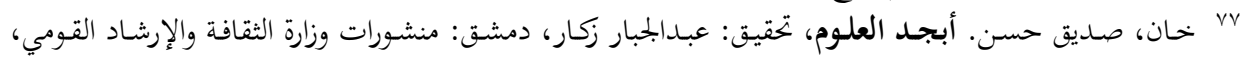

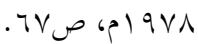


الناطقين بالأردية ترجموا المصطلح الإبحليزي political economy بادئ الأمر بناءً على

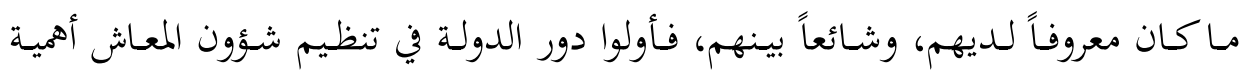

وتُرجمـت بعـد ذلك كتـب أخرى، منها: كتـاب "خطوط عريضـة عن علم الاقتصـاد

السياسي" للاقتصادي البريطاني ناسو وليام سنيور Nassau William Senior تحت

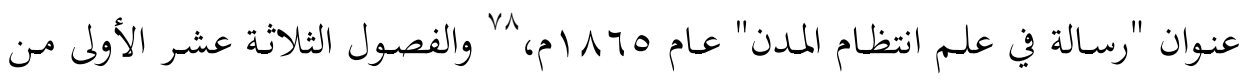
كتـاب "مبـادئ الاقتصـاد السياسي" للاقتصـادي البريطلاني جـون ستوارت ميل John

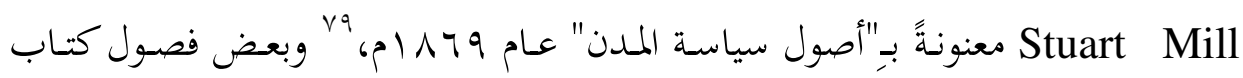
"نظرية الاقتصاد السياسي" للاقتصادي البريطاني وليام جفونس William Jevons عام

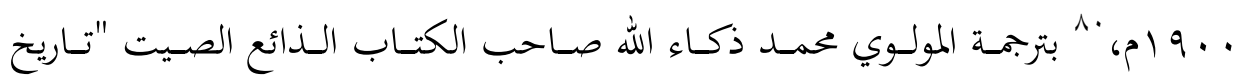

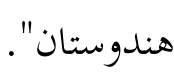

${ }^{78}$ Senior, Nassau William. An Outline of the Science of Political Economy, London: W. Clowes and Sons, 1836, translated to Urdu by Babu Ram Kali Chadhari and Ra'e Shankar Das, Risālah-i 'Ilm-i Intizām-i Mudun, Aligarh: Scientific Society, Syud Ahmud's Private Press, 1865.

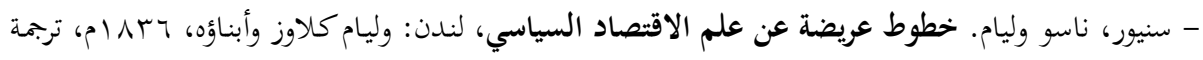

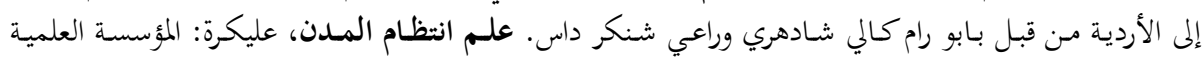

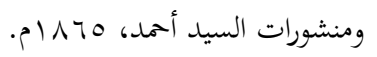

${ }^{79}$ Mill, John Stuart. Principles of Political Economy with some of their Applications to Social Philosophy, London: John W. Parker,1848, translated to Urdu by Pandit Dharam Narayan, Usul-i Siyāsat-i Mudun, Aligarh: Scientific Society, 1869.

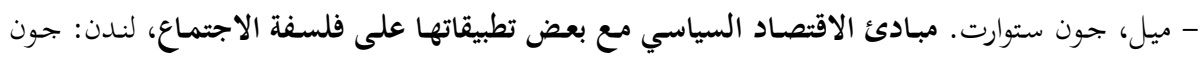

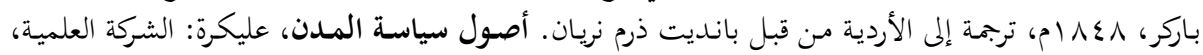

${ }^{80}$ Jevons, William. The Theory of Political Economy, translated to Urdu by Maulvi Muhammad Zakaullah in 1900. See:

- Tahir, Pervez. Introducing Iqbal Economist, The Pakistan Development Review, 40: 4, Part II, Winter 2001, p. 1172.

- جفونس، وليام. نظرية الاقتصاد السياسي، ترجمة إلى الأردية من قبل مولوي محمد زكي الله في عام . .9 ام. 
ولم يكتفِ النـاطقون بالأردية في هذه الحقبـة الزمنيـة بترجمة ما وقفوا عليه مـن كتب

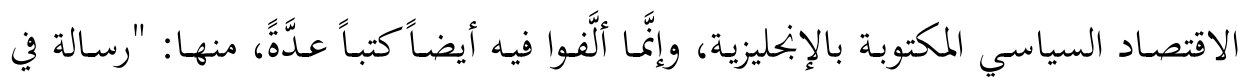

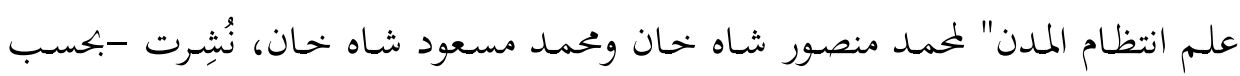

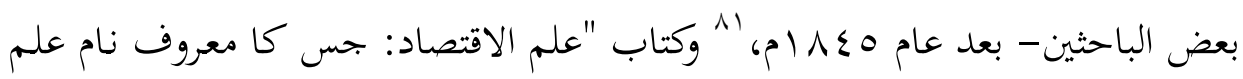

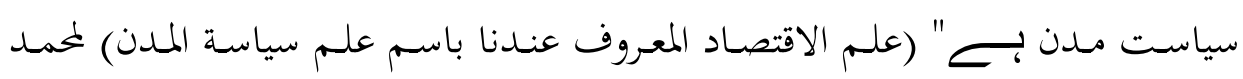

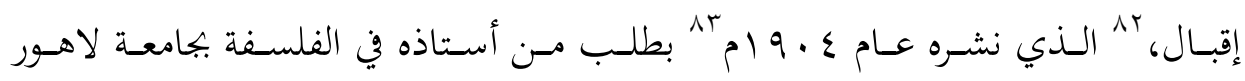
الحلكومية توماس أرنولد Thomas Arnold، مثلما أشار في مقدمة الكتاب، بعد أنْ

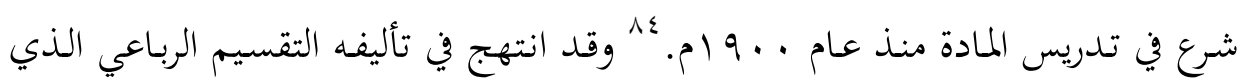
كان متداولاً في أدبيات الاقتصاد السياسي: الإنتاج، والتبادل، والتوزيع، والاستهالك.

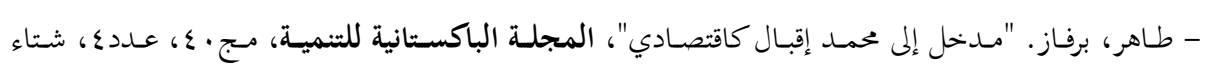

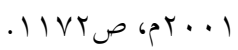

${ }^{81}$ Tahir, Pervez. Op. cit., p. 1172.

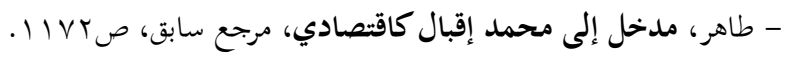

${ }^{82}$ Iqbal, Muhammad. 'Ilm al-Iqtisad, jis ka ma'ruf nam 'Ilm-i Siyasat-i Mudun hae, Lahore: Khadim al-Ta‘lim Steam Press of Paysa Akhbar, December 1904.

- إقبال، محمد. علم الاقتصـاد المعروف عندنا باسم علم سياسة المدن، لاهور: منشورات صحيفة بايسا

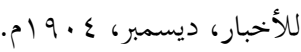

${ }^{83}$ Zaman, Arshad. Sayyid Abu'l A‘la Maududi on Islamic Economics: A Review Article, Islamic Studies, 50:3-4, 2011, p. 307.

- زمان، أرشد. "مراجعة علمية لكتابات السيد أبو الأعلى المودودي في الاقتصاد الإسلامي"، مجلة دراسات

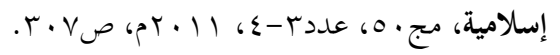

${ }^{84}$ Sevea, Iqbal Singh. The Political Philosophy of Muhammad Iqbal: Islam and Nationalism in Late colonial India, Cambridge: Cambridge University Press, 2010, p. 23.

- سيفيا، إقبال سينغ. الفلسفة السياسية لمحمد إقبال: الإسلام والقومية في أواخر عهد احتلال الهند،

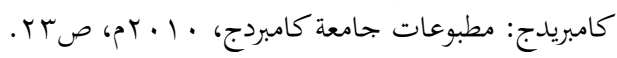

${ }^{85}$ Mir, Mustansir. Iqbal: Makers of Islamic Civilization, London: I.B. Taurus and Oxford University Press India in association with the Oxford Center for Islamic Studies, 2006, p. 19.

- مير، مستنصر. محمدد إقبال: مـن صـناع الحضـارة الإسـلامية، لندن: منشورات أي بي توريس ومطبوعات

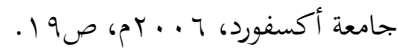


ولعلَّه اعتمد في تأليفه على كتاب "مبادئ علم الاقتصاد" للاقتصادي البريطاني ألفرد

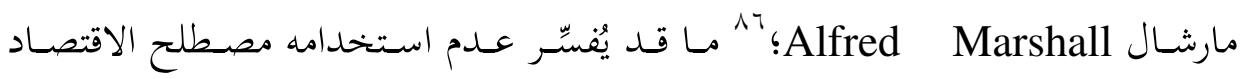

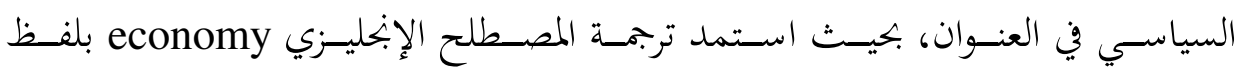

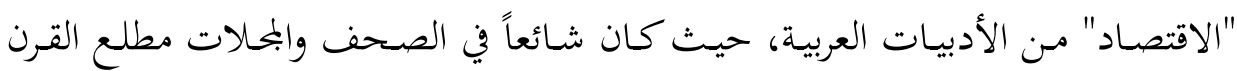

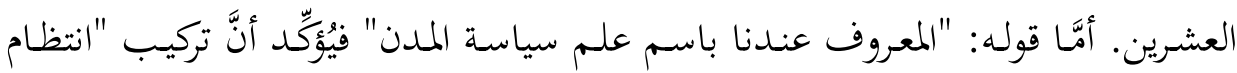

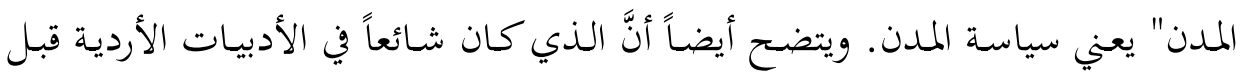

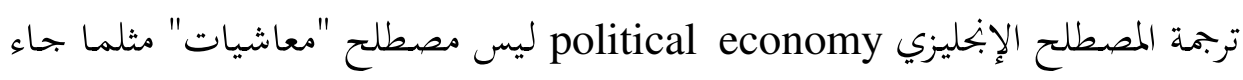
في أدبيات هذا البحث، وإنَّما مصطلح "انتظام المدن".

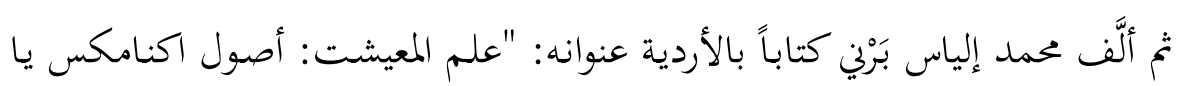

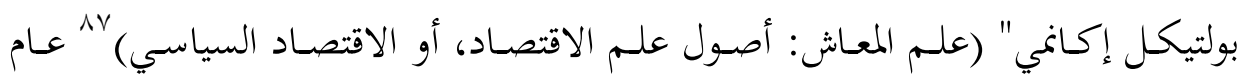
ا l V V

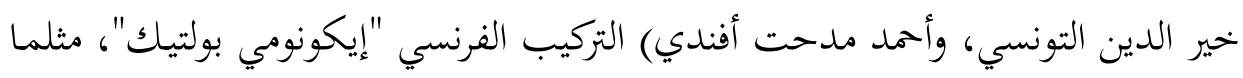

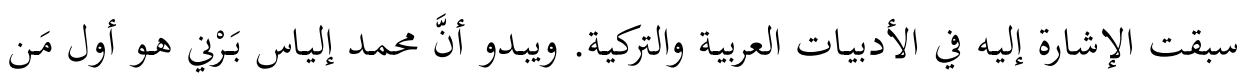

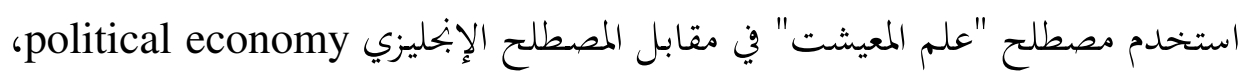

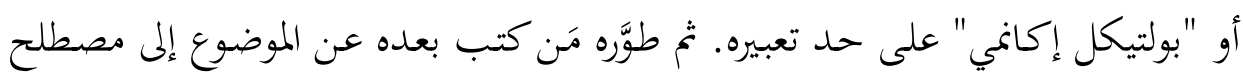
"معاشيات"، مثلما هو شائع اليوم في الأدبيات الأردية.

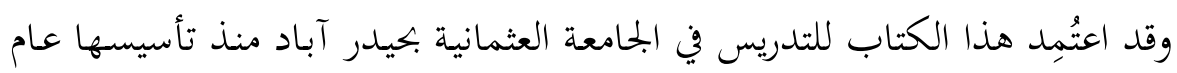

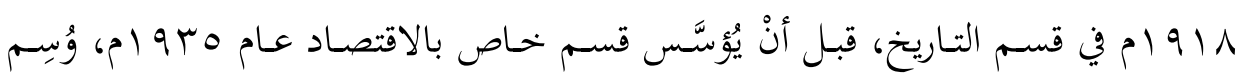

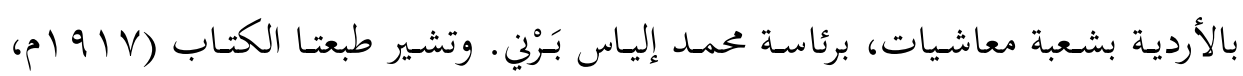

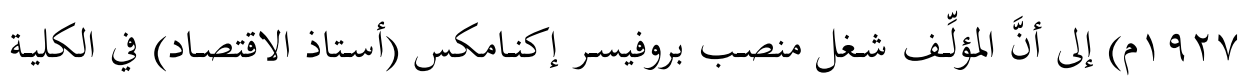

${ }^{86}$ Marshall, Alfred. Principles of Economics, London: Macmillan, 1898.

$$
\text { - مرشال، ألفرد. مبادئ علم الاقتصاد، لندن: منشورات ماكميلان، } 91 \text { ام ام. }
$$

${ }^{87}$ Barni, Muhammad Ilyas. 'Ilm al-Ma ishat: Usul-i Ikanamiks ya Politikal Ikonomi, Aligarh: Matba'-i Institute, 1917.

- برني، محمد إلياس. علم المعاش: أصول علم الاقتصاد أو الاقتصاد السياسي، عليكرة: مطبعة المعهد، 


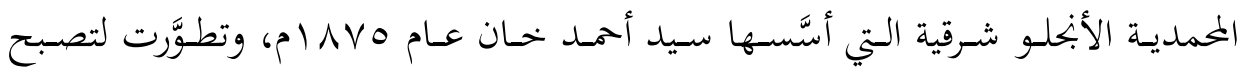

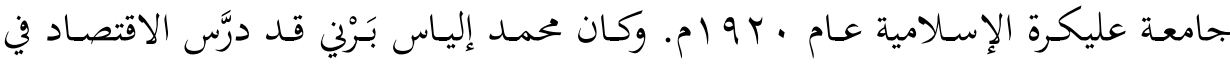

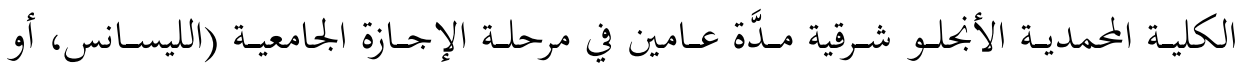

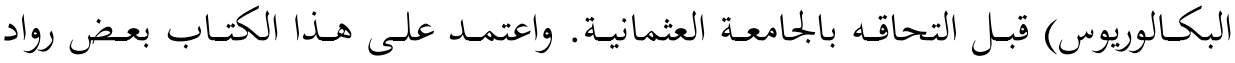

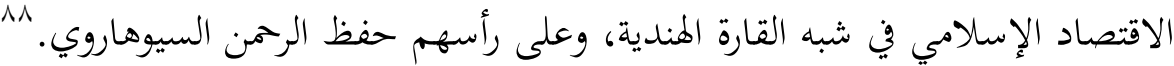
يتبيَّن مُّّا سبق أنَّ مصطلح الاقتصاد السياسي قد دخل الأدبيات الأردية عن طريق

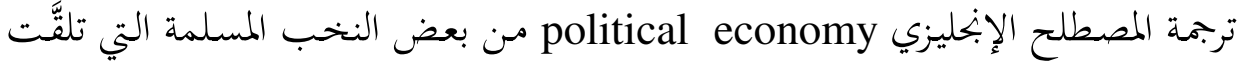

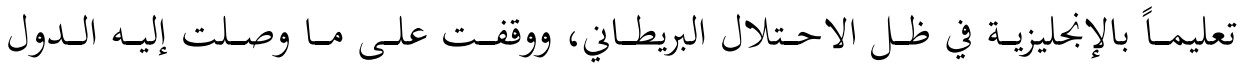

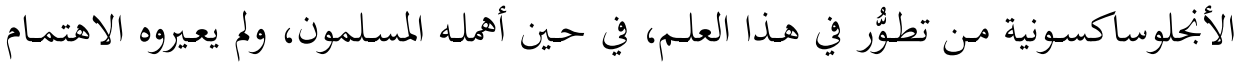

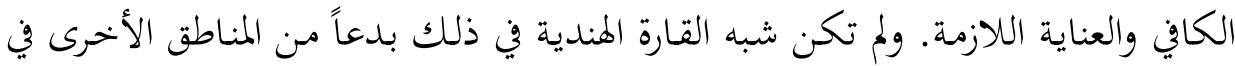

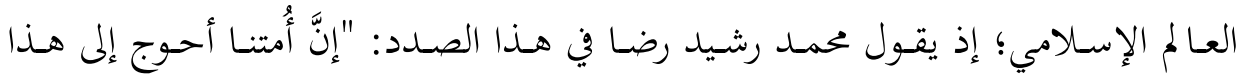

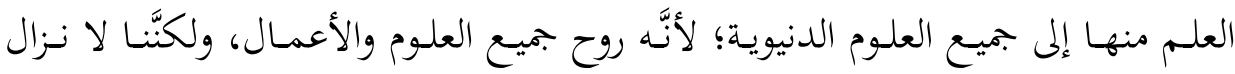
مقصرين فيه بقدر حاجتنا إليه." ويعرض الجـدول رقم (ع ) مؤلفـات الاقتصـاد السياسي التي ظهـرت في الأدبيـات

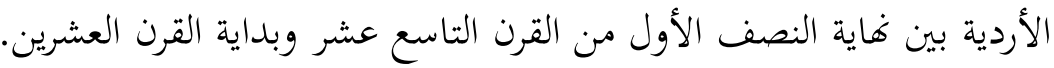
الجحدول (ع): مؤلفات الاقتصاد باللغة الأردية في الفترة الممتدة بين غاية النصف

\begin{tabular}{|c|c|c|c|c|}
\hline مكان & سنة النشر & الكناب & العنوان بالأردية & المؤلّف \\
\hline دلمي & blᄉst & ترجمة & أصول بولتيكل إكانمي & مؤلف غير مذكور \\
\hline دلمي & plᄉ & ترجمة & أصول علم انتظام المدن & فرنسيس ويلاند \\
\hline
\end{tabular}

${ }^{88}$ Savharvi, Hafz-ur-Rehman. The Economic System of Islam, Lahore: Idara-e-Islamiat, 2001, p. 20.

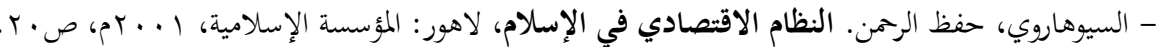

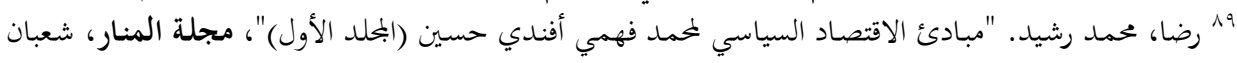

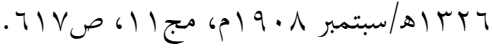



نشأة مصطلح الاقتصاد السياسي في العالم الإسلامي

\begin{tabular}{|c|c|c|c|c|}
\hline 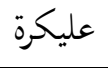 & plᄉ70 & ترجمة & رسالة في علم انتظام المدن & ناسو وليام سنيور \\
\hline عليكرة & p) 1179 & ترجمة & أصول سياسة المدن & جون ستوارت ميل \\
\hline بجهول & بعد سنة & 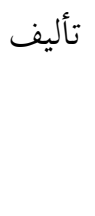 & رسالة في علم انتظام المدن & محمد منصور شاه \\
\hline 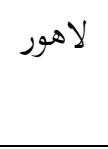 & $p 19 \cdot \varepsilon$ & 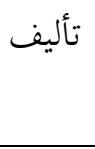 & علم الاقتصاد المعروف عندنا باسم & محمد إقبال \\
\hline عليكرة & p191V & 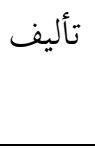 & الاقتصاد، أو الاقتصاد الميشات: أصول علم & محمد إلياس بَرْني \\
\hline
\end{tabular}

خاتمة:

دخـل مصسطلحُ الاقتصـاد السياسـي العـالمُ الإسـلامي عـن طريـق ترجمـة المصـطلح

الفرنسي économie politique، أو المصطلح الإبحليزي political economy.

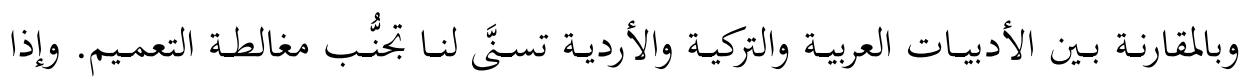

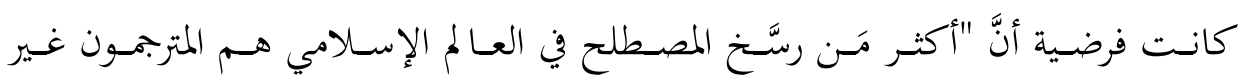

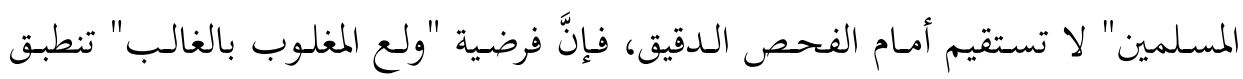
على بعض الدول المسلمة، لكنّها لا تنطبق على العالم الإسلامي أجمع؛ ما يجعل الفرضية الأخيرة أكثر ملاءمة، وهي أنَّ ترجمة المصطلح مردُّها إهمال المسلمين العلوم الاجتماعية،

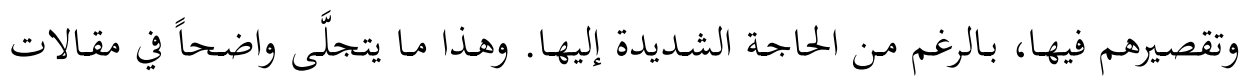
محمد رشيد رضا في بحلة المنار بخصوص علم الاقتصاد السياسي. وقــ تزامنـت حركة الاهتمـام بالاقتصـاد السياسي مع معاينـة النخـب المثتفـة العربيـة

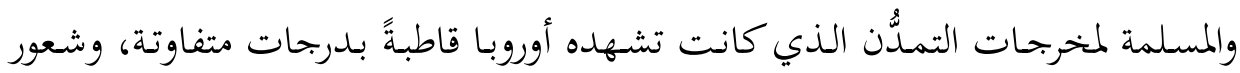
أفراد هذه النخب أنَّ تدابير الحياة المعيشية التي كانت تتخذها دولهم لا تستند إلى نظرية

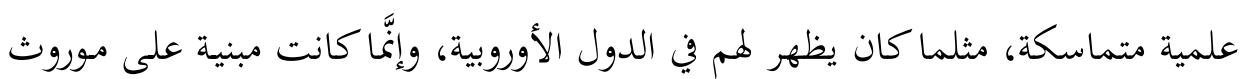




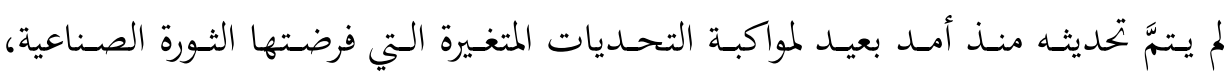

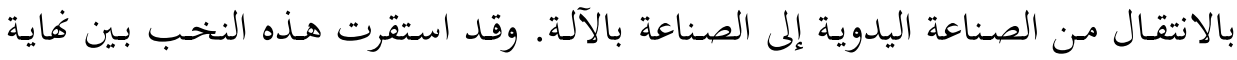

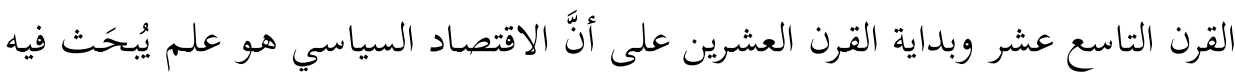

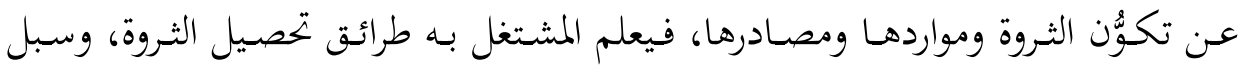

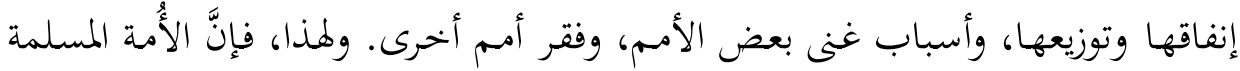

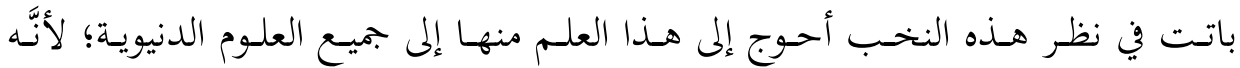

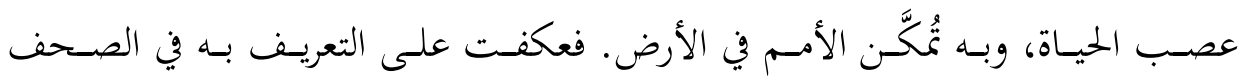

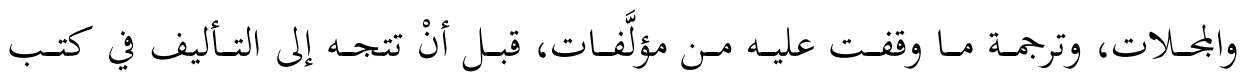

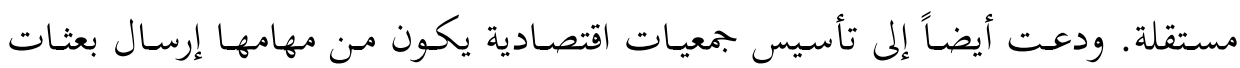
طلابية إلى الجامعات الأوروبية لتحصيل ما أمكن منه.

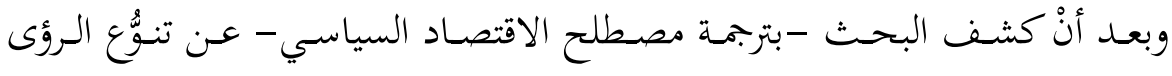

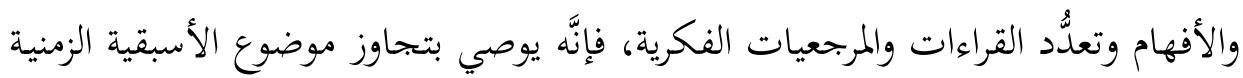

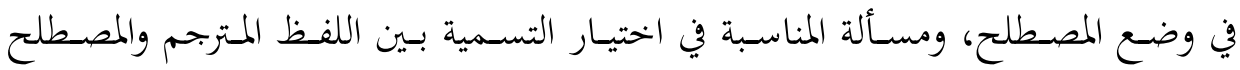

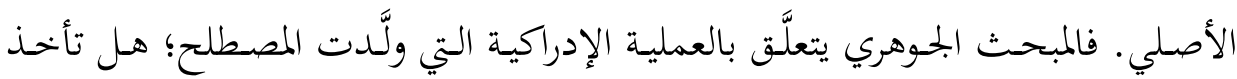

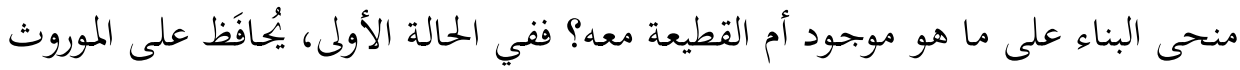

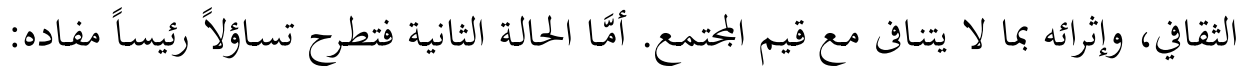

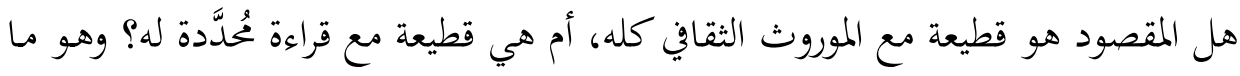

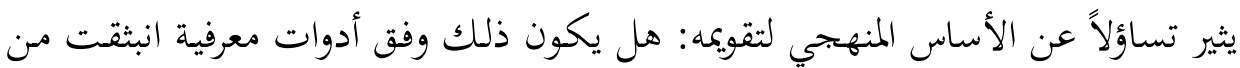

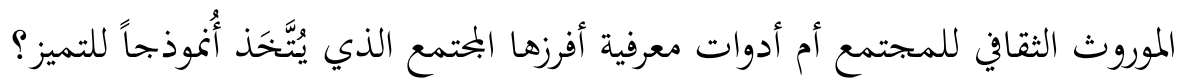

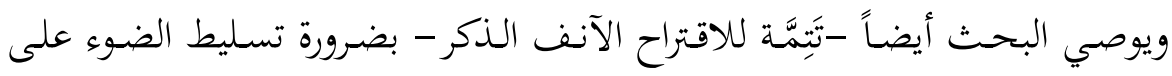

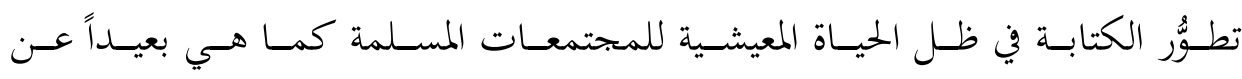

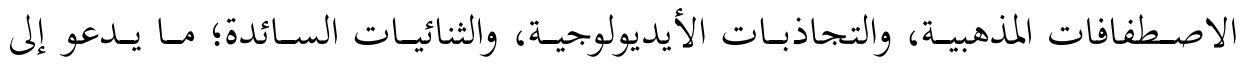

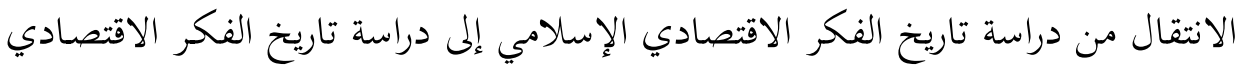

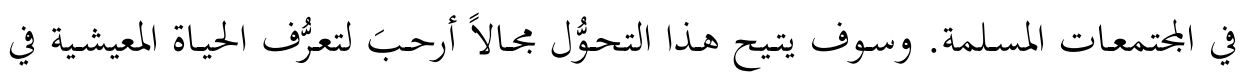


المجتمعـات المسـلمة، بالتنـاغم مـع تطوُرات البحـث العلمي التي تولي الجوانـب التاريخيـة

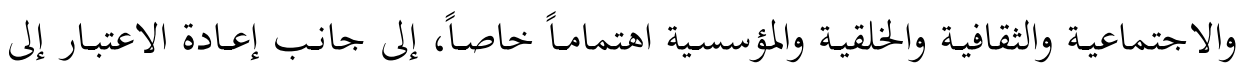

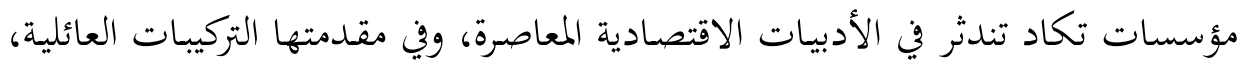

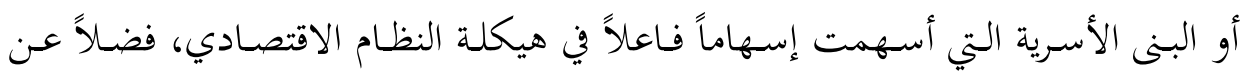

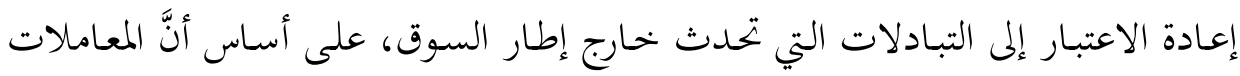

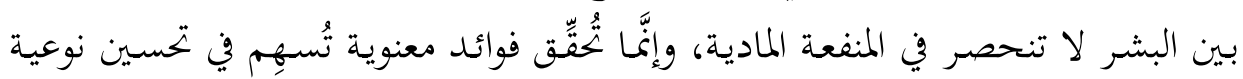

\section{الملحق}

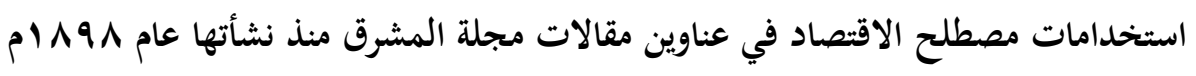
حتى بداية القرن العشرين

\begin{tabular}{|c|c|c|c|c|}
\hline 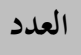 & 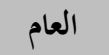 & 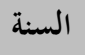 & 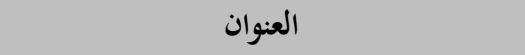 & 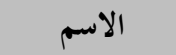 \\
\hline v & $p 19 \cdot r$ & $\circ$ & منافع السكة البغدادية: نظر تجاري اقتصادي & 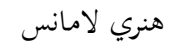 \\
\hline tr & p19. & v & لمحة اقتصادية في بحاري المياه اللبنانية & هنري لامانس ل \\
\hline rt & $p 1 q \cdot \varepsilon$ & v & لمحة اقتصادية في بحاري المياه اللبنانية & 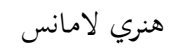 \\
\hline$\wedge$ & p19.0 & $\wedge$ & النفق الجديد بين إيطالية وسويسرة: نبذة تاريخية & لويس شيخو \\
\hline ○ & $p 19 \cdot v$ & 1. & لبنان: نظر في أشغاله العمومية وزراعته ومستقبله & إميل خاشو سر \\
\hline 7 & $p 1 q \cdot v$ & $1 \cdot$ & لبنان: نظر في أشغاله العمومية وزراعته ومستقبله & إميل خاشو سر \\
\hline$\checkmark$ & $p 19 \cdot v$ & $1 \cdot$ & لبنان: نظر في أشغاله العمومية وزراعته ومستقبله & إميل خاشو سر \\
\hline$\wedge$ & $p 19 \cdot v$ & 1. & لبنان: نظر في أشغاله العمومية وزراعته ومستقبله & إميل خاشو سر \\
\hline 9 & $519 \cdot v$ & 1. & لبنان: نظر في أشغاله العمومية وزراعته ومستقبله & إميل خاشو سر \\
\hline 11 & $p 19 \cdot v$ & $1 \cdot$ & نخل العراق وتمره: نظر زراعي واقتصادي & يوسف غنيمة \\
\hline
\end{tabular}




\begin{tabular}{|c|c|c|c|c|}
\hline 1. & p191. & ir & تأمين الحياة: نظر تاريخي واقتصادي & الكونت دوجو \\
\hline 1. & 51911 & $1 \varepsilon$ & مركز الولايات المتحدة الاقتصادي & مفروماتيس \\
\hline$\wedge$ & pla1r & 10 & العسل: نظر صناعي اقتصادي & $\begin{array}{l}\text { إسكندر طوران } \\
\text { اليسوعي }\end{array}$ \\
\hline 1 & 31914 & 10 & النحل: نظر علمي عملي اقتصادي & إسكندر طوران \\
\hline r & b191r & 10 & النحل: نظر علمي عملي اقتصادي & إسكندر طوران \\
\hline v & b19r| & 19 & معرض بيروت: إجمالي تاريخي اقتصادي اجتماعي & لويس شيخو \\
\hline v & p19r1 & 19 & مسألة البترول: نظر تاريخي واقتصادي & رفائيل نخلة اليسوعي \\
\hline 9 & plart & $r \varepsilon$ & حاضرة سان باولو في البرازيل: نظر تاريخي & جرجس إليان \\
\hline$\varepsilon$ & blarv & ro & الأحوال الاقتصادية في سورية الرومانية & رينه موترد اليسوعي \\
\hline$\varepsilon$ & blarv & ro & تعميم الاصطياف في لبنان: نظر اجتماعي & لويس شيخو \\
\hline ir & p|9r| & $r q$ & دير الزور والحالة الاقتصادية في لواء الفرات & جوزف توتل \\
\hline v & plart & $r$. & جولة في المجلات: بحث في أملاك الدولة والحالة & محرّر المحلة \\
\hline$r$ & plarr & $r$. & حالة لبنان الاقتصادية في سنة اسبو ام & إبراهيم عواد \\
\hline r & 190r & $\varepsilon v$ & مات الاتحاد اللبناني السوري الاقتصادي: ليعش & إرنست تلياك \\
\hline- & p1991 & 70 & التعليم الأساسي والتنمية الاقتصادية والاجتماعية & بطرس لبكي \\
\hline 1 & p1991 & Vr & علاقات الاتحاد الأوربي الاقتصادية ببلدان جنوب البحر المتوسط وشرقه & جان دكرويه \\
\hline$r$ & pral & vo & 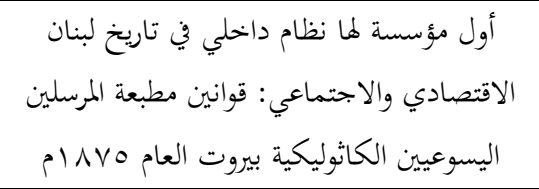 & هيام ملاط \\
\hline
\end{tabular}

